\title{
A design methodology for side wall failure of RHS truss $X$-joints accounting for compressive chord pre-load
}

Cheng, S

http://hdl.handle.net/10026.1/10581

10.1016/j.engstruct.2016.08.019

Engineering Structures

All content in PEARL is protected by copyright law. Author manuscripts are made available in accordance with publisher policies. Please cite only the published version using the details provided on the item record or document. In the absence of an open licence (e.g. Creative Commons), permissions for further reuse of content should be sought from the publisher or author. 


\section{A design methodology for side wall failure of RHS truss $\mathrm{X}$-joints accounting for compressive chord pre-load}

Article in Engineering Structures · November 2016

DOI: $10.1016 /$ j.engstruct.2016.08.019

2 authors, including:

\section{Shanshan Cheng}

The University of Sheffield

14 PUBLICATIONS 17 CITATIONS

SEE PROFILE 


\title{
A design methodology for side wall failure of RHS truss X-joints accounting for compressive chord pre-load
}

\author{
Shanshan Cheng *, Jurgen Becque \\ Department of Civil and Structural Engineering, The University of Sheffield, Sheffield, UK
}

\section{A R T I C L E I N F O}

Article history:

Received 17 March 2016

Received in revised form 8 June 2016

Accepted 10 August 2016

Available online $\mathrm{xxx}$

Keywords:

Hollow sections

Connections

Joints

Side wall buckling

Chord pre-load

RHS

SHS

Design

\section{A B S T R A C T}

This paper presents a design methodology for equal-width RHS X-joints failing by side wall buckling, with a particular focus on the effect of a compressive chord pre-load. A slenderness parameter is thereby defined based on the elastic local buckling stress of the side wall, idealized as an infinitely long plate under a patch loading transferred from the brace member in combination with a uniform chord pre-load. A Rayleigh-Ritz approximation is used to obtain a closed form solution. The proposed design equation is verified against finite element results over a wide range of wall slenderness values and is demonstrated to yield excellent predictions. Finally, a reliability analysis is performed using the first order reliability method (FORM) within the framework of both the Eurocode and the AISC Specification to ensure the proposed equation possesses the required level of safety. The proposed equation strongly outperforms the current CIDECT design rule for side wall buckling and also further extends the range of applicability to a wall slenderness ratio of up to 50 .

CC 2016 Published by Elsevier Ltd.

\section{Introduction}

Structural hollow sections with a rectangular, square or circular cross-section are widely used in engineering structures because of their favourable properties, such as a high structural efficiency in compression and bending, a high strength and stiffness in torsion, an aesthetic appeal, a reduced exposed area and a reduced drag coefficient in fluid flow [1]. Rectangular hollow sections (RHS) are often favoured over circular sections because of the reduced complexity of manufacturing the connections. RHS have important applications in truss structures which are often found in large roof spans, pedestrian bridges, walkways and offshore structures. In the design of these trusses the joints require particular attention as they are susceptible to a number of particular failure modes. Research on welded hollow section joints has been carried out for many decades and CIDECT (Comité International pour le Développement et l'Etude de la Construction Tubulaire) has been very instrumental in this. The design rules for hollow section joints issued (and regularly upgraded) by CIDECT have been adopted by all major design standards around the world. The most recent version of the design rules can be found in [2].

This paper focuses on right angle $\mathrm{X}$-joints between equal-width RHS truss members subject to brace compression and a compressive chord pre-load. It is noted that this paper follows the established CIDECT nomenclature, where $h_{0}$ and $h_{1}$ are the chord height and the

\footnotetext{
* Corresponding author
}

Email address: shanshan.cheng@sheffield.ac.uk (S. Cheng) brace height, respectively, $b_{0}$ and $b_{1}$ represent the chord width and the brace width, respectively, and $t_{0}$ and $t_{1}$ refer to the thicknesses of the chord wall and the brace wall, respectively (Fig. 1).

For these types of joints, side wall failure of the chord member is critical, either by buckling or by localized plastification under the brace (bearing failure). In the current CIDECT design rules, this is essentially accounted for by isolating a vertical strip in the chord side wall and designing it as a column [3]. A chord load function $\mathrm{Q}_{\mathrm{f}}$ is then applied to account for the effect of a chord pre-load. While defendable because of its simplicity, this approach obviously ignores the two-dimensional character of the side wall which acts as a plate under bi-directional stresses.

It is common in experimental work to determine the capacity of an X-joint as the minimum of either the peak load or the load corresponding to the $0.03 \mathrm{~b}_{0}$ deformation limit [4] after carrying out a test on an isolated connection. However, recently a compelling case has been made to limit the joint capacity to the load at which side wall buckling first occurs $[5,6]$. This rationale is based on the observation that, in the design of CHS and RHS trusses, completely separate and uncoupled checks are carried out for the stability of the truss members on one hand and the capacity of the truss joints on the other. It is thereby entirely conceivable that a truss member is continuous over a joint (e.g. in the case of a chord member or a through-member in an X-brace) without the truss member being supported out-of-plane at that particular joint. The out-of-plane effective length of that specific truss member would thus include one or more joint locations. If side wall buckling were to take place in one of those joints, it would locally severely reduce the longitudinal compressive capacity of the side walls (theoretically in the order of $60 \%$ for the elastic case and 


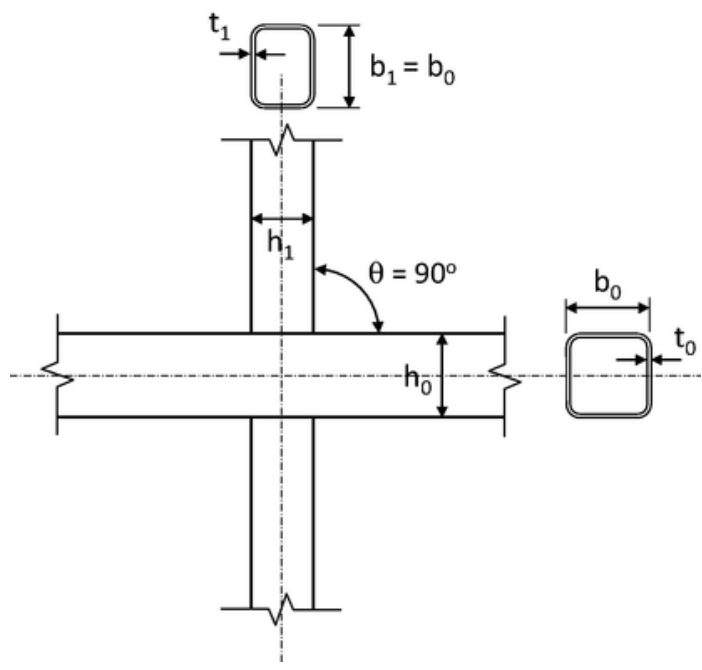

Fig. 1. Connection geometry.

idealized boundary conditions [7]) and, by consequence, the out-of-plane buckling capacity of the truss member through the introduction of a weak link. Since the truss member checks are carried out based on the assumption of a 'sound' cross-section displaying no local buckling, a safe (although in most cases somewhat conservative) design approach consists of limiting the joint capacity to the side wall buckling load. This philosophy has been adopted in the here proposed methodology.

Furthermore, it has been known for some time that the current CIDECT design rules for chord side wall failure are quite conservative, and more so as the chord wall slenderness $h_{0} / t_{0}$ increases [8]. The aim of this paper is therefore to present an alternative design equation for chord side wall buckling, equally simple in its application as the current CIDECT rule, but founded on a rational plate buckling model and verified against numerical and experimental data.

In previous research, 31 tests on equal-width $\mathrm{X}$-joints were carried out by Packer [3]. The brace members thereby consisted of either RHS members or simple plates welded to the chord. Both hot-formed and cold-formed RHS tubes were considered and the wall slenderness values $\left(h_{0} / t_{0}\right)$ in the tests ranged from 15.3 to 42.2 . The effects of the brace member angle $\theta$ (Fig. 1) and the compressive chord pre-load were investigated and the research resulted in the proposition of a unified equation for both T- and X-joints. However, neither the chord depth $\left(h_{0}\right)$ nor the axial chord preload were explicitly included in the equation, as they were believed to have little effect on the ultimate strength of the joints. At a later stage, Davies and Packer [9] rejected this conclusion and instead postulated that the joint strength depends on the chord slenderness $\left(\mathrm{h}_{0} / \mathrm{t}_{0}\right)$ and the non-dimensional bearing length $\left(\mathrm{h}_{1} / \mathrm{h}_{0}\right)$.

Wardenier [10,11] conducted tests on RHS T- and X-joints, with the brace members loaded either in tension or compression, but without a compressive load in the chord. Both hot finished and cold finished hollow sections of grades S235 and S275 were included in the programme. It was concluded that for equal-width X-joints, the compressive strength of the joint is limited by either a bearing or a buckling failure mode in the chord side walls. The authors provided a unified equation for both failure modes, in which the buckling stress is derived from the model of a pin-ended strut with an effective length of $\left(h_{0}-2 t_{0}\right)$. This approach formed the basis of the current CIDECT design rule.

Through a series of experimental and numerical studies on RHS $\mathrm{X}$-joints carried out by $\mathrm{Yu}$ [12], it was found that the effect of an axial chord pre-load on the ultimate capacity of an X-joint decreases with increasing $\beta$ values, where $\beta=b_{1} / b_{0}$. For full-width $\mathrm{X}$-joints $(\beta=1)$ the effect was found to be very small. At the same time, however, it was discovered that the influence of the axial pre-load increases with increasing side wall slenderness. The numerical results by $\mathrm{Yu}\lceil 12\rceil$ formed the basis of the chord stress function $\mathrm{Q}_{\mathrm{f}}$ for side wall failure in the CIDECT design guide [2].

Recently, experimental and numerical studies have been carried out by Becque and co-workers [5,6] to develop an alternative design equation for chord side wall failure of equal-width RHS X-joints, founded on a rational plate buckling model. The proposed design equation showed excellent agreement with experimental and numerical results, but did not account for a compressive chord load. In this paper, the research is extended and a model founded on the same principles is developed which also includes the effect of a compressive chord pre-load. Detailed numerical models, first validated against experimental data, were employed to carry out parametric studies and generate numerical data. These data were subsequently used to validate the proposed design model.

\section{Analytical model}

A rational model was developed in which the chord side wall was idealized as an infinitely long plate simply supported along both longitudinal edges and subject to a transverse localized stress $\sigma_{1}$ (originating from the brace members) and a longitudinal compressive stress $\sigma_{2}$ (Fig. 2). The plate was assumed to be made of a linear elastic, isotropic and homogeneous material with thickness $t_{0}$. The loads and boundary conditions were idealized as follows:

1. It was assumed that the vertical load transferred from the brace side wall is uniformly distributed over the brace width $h_{1}$. The total vertical load carried by the connection (two side walls) is then given by:

$$
P_{1}=2 \sigma_{1} t_{0} h_{1}
$$

2. The chord preload $P_{2}$ is uniformly distributed over the cross-section of the chord member:

$P_{2}=2 \sigma_{2} t_{0}\left(h_{0}+b_{0}\right)$

3. The plate is hinged along both longitudinal edges. This is a conservative assumption, neglecting any restraint provided by the chord top and bottom faces and by the welded connection with the brace member.

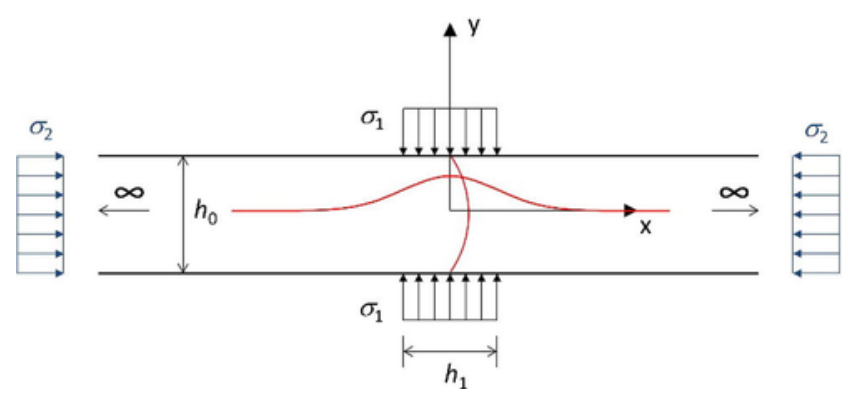

Fig. 2. Idealized model. 
A Rayleigh-Ritz approach was used to approximate the critical buckling stress of the chord side wall. The exponential Gauss function was thereby chosen to represent the longitudinal shape of the buckle. This function descends to zero almost immediately when moving outside a narrow region around the origin and thus captures the localized nature of the failure mode very well. When also adopting a half-sine wave solution in the transverse direction (across the depth of the chord wall), the proposed deformed shape is expressed by the following multiplicative function:

$$
w=\Delta \cos \left(\frac{\pi y}{h_{0}}\right) e^{-2 B x^{2}}
$$

where $w$ is the out-of-plane displacement of the plate, and $\Delta$ and $B$ are presently undetermined parameters. $\Delta$ determines the amplitude of the displacements, while $B$ is related to the length of the local buckle. The Gauss function features prominently in statistics and from the study of the Gaussian (normal) distribution it is known that only $0.27 \%$ of the points in the distribution are more than three standard deviations removed from the average. A comparison between Eq. (3) and the standard expression of the Gaussian distribution:

$$
f(x, \mu, s)=\frac{1}{s \sqrt{2 \pi}} e^{-\frac{(x-\mu)^{2}}{2 s^{2}}}
$$

where $\mu$ is the average and $s$ is the standard deviation, yields an approximate length of the buckle:

$$
L_{b}=6 s=\frac{3}{\sqrt{B}}
$$

The elastic strain energy $U$ contained in the deformed shape of the plate is given by (e.g. Timoshenko and Gere [13]):

$$
\begin{aligned}
U= & \frac{D}{2} \int_{x=-\infty}^{x=\infty} \int_{y=-h_{0} / 2}^{y=h_{0} / 2}\left\{\left(\frac{\partial^{2} w}{\partial x^{2}}\right)^{2}+\left(\frac{\partial^{2} w}{\partial y^{2}}\right)^{2}\right. \\
& \left.+2 v\left(\frac{\partial^{2} w}{\partial x^{2}}\right)\left(\frac{\partial^{2} w}{\partial y^{2}}\right)+2(1-v)\left(\frac{\partial^{2} w}{\partial x \partial y}\right)^{2}\right\} d x d y
\end{aligned}
$$

In the above equation, $D$ is the flexural rigidity of the plate, given by:

$$
D=\frac{E t_{0}^{3}}{12\left(1-v^{2}\right)}
$$

where $E$ is the modulus of elasticity and $\nu$ is the Poisson's ratio. Substitution of Eq. (3) into Eq. (6) requires computation of the following integrals:

$$
\begin{aligned}
& \int_{-\infty}^{\infty} x^{2} e^{-4 B x^{2}} d x=\frac{1}{16 B} \sqrt{\frac{\pi}{B}} \\
& \int_{-\infty}^{\infty} x^{4} e^{-4 B x^{2}} d x=\frac{3}{128 B^{2}} \sqrt{\frac{\pi}{B}}
\end{aligned}
$$

and eventually leads to the following expression for the elastic strain energy $U$ :

$$
U=\frac{\Delta^{2} D}{2} \sqrt{\frac{\pi}{B}}\left(3 B^{2} h_{0}+B \frac{\pi^{2}}{h_{0}}+\frac{\pi^{4}}{4 h_{0}^{3}}\right)
$$

The potential energy of the applied stresses, on the other hand, is given by:

$$
\begin{aligned}
V= & -\frac{\sigma_{1} t_{0}}{2} \int_{x=-h_{1} / 2}^{x=h_{1} / 2} \int_{y=-h_{0} / 2}^{y=h_{0} / 2}\left(\frac{\partial w}{\partial y}\right)^{2} d x d y \\
& -\frac{\sigma_{2} t_{0}}{2} \int_{x=-\infty}^{x=\infty} \int_{y=-h_{0} / 2}^{y=h_{0} / 2}\left(\frac{\partial w}{\partial x}\right)^{2} d x d y
\end{aligned}
$$

or, after substituting Eq. (3) into Eq. (11):

$$
V=-\frac{\Delta^{2} \sigma_{1} t_{0} \pi^{2}}{4 h_{0}} \int_{x=-h_{1} / 2}^{x=h_{1} / 2} e^{-4 B x^{2}} d x-\frac{\Delta^{2} \sigma_{2} t_{0} h_{0}}{4} \sqrt{\pi B}
$$

The remaining integral in Eq. (12) has no closed form solution and can only be expressed as a series:

$$
\int_{x=-h_{1} / 2}^{x=h_{1} / 2} e^{-4 B x^{2}} d x=h_{1}-\frac{h_{1}^{3} B}{3}+\cdots
$$

Only the first term in the series is retained, so that:

$V=-\frac{\Delta^{2} \sigma_{1} t_{0} \pi^{2}}{4 h_{0}} h_{1}-\frac{\Delta^{2} \sigma_{2} t_{0} h_{0}}{4} \sqrt{\pi B}$

Neglecting the higher order terms in Eq. (13) is acceptable, provided that:

$$
\frac{h_{1}^{3} B}{3}<<h_{1} \quad \text { or } \quad \frac{h_{1}^{2} B}{3}<<1
$$

It will be shown at a later stage (once an expression for $B$ has been determined) that this is indeed a reasonable assumption.

In order to minimize the total energy $U+V$, its derivatives with respect to $B$ and $\Delta$ are set equal to zero:

$$
\frac{\partial(U+V)}{\partial B}=0
$$

$$
\frac{\partial(U+V)}{\partial \Delta}=0
$$

Eqs. (16) and (17) eventually yield: 


$$
\begin{aligned}
B=\frac{1}{18}\left\{\frac{\sigma_{2} t_{0}}{2 D}\right. & -\left(\frac{\pi}{h_{0}}\right)^{2} \\
& \left.+\sqrt{\left[\left(\frac{\pi}{h_{0}}\right)^{2}-\frac{\sigma_{2} t_{0}}{2 D}\right]^{2}+9\left(\frac{\pi}{h_{0}}\right)^{4}}\right\}
\end{aligned}
$$

and:

$$
\begin{aligned}
& \sigma_{c r}=\frac{1}{2 t_{0} h_{1}} \sqrt{\frac{\pi}{B}}\left\{12 D\left(\frac{h_{0}}{\pi}\right)^{2} B^{2}\right. \\
&\left.+4\left[D-\frac{\sigma_{2} t_{0}}{2}\left(\frac{h_{0}}{\pi}\right)^{2}\right] B+D\left(\frac{\pi}{h_{0}}\right)^{2}\right\}
\end{aligned}
$$

In case $\sigma_{2}=0$, indicating that there is no chord preload, Eq. (18) becomes:

$$
B=\left(\frac{\sqrt{10}-1}{18}\right)\left(\frac{\pi}{h_{0}}\right)^{2}=\frac{1.186}{h_{0}^{2}}
$$

which is consistent with the value previously obtained in [6] in the absence of chord pre-compression.

After introducing $\frac{\sigma_{2} t_{0}}{2 D}=a\left(\frac{\pi}{h_{0}}\right)^{2}$, Eqs. (17) and (18) can be more succinctly written as:

$$
\begin{aligned}
& B=\frac{\sqrt{9+(1-a)^{2}}-(1-a)}{18}\left(\frac{\pi}{h_{0}}\right)^{2} \\
& \sigma_{c r}=\frac{D}{2 t_{0} h_{1}} \sqrt{\frac{\pi}{B}}\left[12 B^{2}\left(\frac{h_{0}}{\pi}\right)^{2}+4(1-a) B+\left(\frac{\pi}{h_{0}}\right)^{2}\right]
\end{aligned}
$$

in which:

$$
a=\frac{\sigma_{2} t_{0}}{2 D}\left(\frac{h_{0}}{\pi}\right)^{2}
$$

Since the brace load is assumed to be uniformly distributed over the brace width $h_{1}$, the critical elastic buckling load of the X-joint is obtained from the following equation:

$$
\begin{aligned}
P_{c r} & =2 t_{0} h_{1} \sigma_{c r} \\
& =D \sqrt{\frac{\pi}{B}}\left[12 B^{2}\left(\frac{h_{0}}{\pi}\right)^{2}+4(1-a) B+\left(\frac{\pi}{h_{0}}\right)^{2}\right]
\end{aligned}
$$

The condition in Eq. (15) can now be evaluated. Substituting Eq. (21) into Eq. (15) yields:

$$
\left(\frac{h_{1}}{h_{0}}\right)^{2}<<\frac{54}{\pi^{2}\left[\sqrt{9+(1-a)^{2}}-(1-a)\right]}
$$

The parameter $a$ is typically smaller than 2 in practical applications, with $a=2$ (corresponding, for instance, to $\mathrm{h}_{0} / \mathrm{t}_{0}=50$ and $\sigma_{2}=290 \mathrm{MPa}$ ) yielding the most critical value for Eq. (25):

$\frac{h_{1}}{h_{0}}<1.13$

Given the fact that the chord member is typically the larger member compared to the braces (or at most of equal size), $h_{1} / h_{0}$ usually satisfies Eq. (26) and, consequently, Eq. (15).

\section{Finite element modelling}

Since there is a profound lack of experimental data related to side wall failure of RHS X-joints with a compressive load applied to the chord, the Finite Element (FE) method was employed in this study to investigate the effect of a chord pre-load. The finite element model was developed in Abaqus [14] and was first benchmarked against nine experimental results X1-X9 involving equal-width RHS X-joints with no chord preload applied, obtained from $[6,8]$.

The model incorporated the measured dimensions, geometric imperfections and weld sizes, the values of which can be found in Table 1 and $[15,16]$. Material properties obtained from coupon test results were included in the model. The material yield stresses $f_{y}$ and ultimate strengths $f_{u}$ are listed in Table 1 . Note that the reported values are engineering stresses. For the weld material, a bilinear stress-strain relationship was used, based on the nominal material properties $\left(f_{y}=460 \mathrm{MPa} ; f_{u}=600 \mathrm{MPa}\right)$, as shown in Fig. 3. Fig. 3 also shows the measured stress-strain curves of the S355 steel, used to model $\mathrm{X} 1-\mathrm{X} 5$, and the C450 steel, used for X6-X9.

Boundary conditions consistent with the experiment were applied to the FE models. Except for specimens X6 and X7, the brace ends were fixed (prevented from lateral displacement and overall rotation), while uniform longitudinal displacements were imposed on the specimen. Specimens X6 and X7 were tested between hinged boundary conditions [8]. In those cases, rigid body constraints were used to tie all nodes in the brace end sections to the centroids of those cross-sections and rotations about the centroid were allowed. Symmetric boundary conditions were applied where possible, which typically meant $1 / 8$ of the connection was modelled (unless asymmetric chord imperfections were measured).

'Tie constraints' were used to fuse the surfaces between the welds and the brace and chord members together. The weld surfaces were thereby used as the master surfaces in all constraints.

3D solid elements were employed and three elements were used in the through-thickness direction of the RHS walls. Hexahedral elements were used throughout the model, except for the welds where tetrahedral elements were chosen due to the complexity of the geometry. A global mesh size of twice the thickness of the chord was used, while a finer mesh size of about $2 / 3$ of the chord wall thickness was chosen for the region of the chord side wall under the brace members, where side wall failure was expected to occur (Fig. 4).

The influence of the mesh size, the element type (i.e. linear vs. quadratic elements), and the analysis solver were investigated in a sensitivity study using test X7. A total of 10 models were run, cov- 
Table 1

Measured dimensions.

\begin{tabular}{|c|c|c|c|c|c|c|c|c|c|c|c|c|c|c|}
\hline Label & $\begin{array}{l}\text { Nominal chord } \\
\text { size }\end{array}$ & $\begin{array}{l}\text { Nominal brace } \\
\text { size }\end{array}$ & $\begin{array}{l}h_{0} \\
(\mathrm{~mm})\end{array}$ & $\begin{array}{l}b_{0} \\
(\mathrm{~mm})\end{array}$ & $\begin{array}{l}t_{0} \\
(\mathrm{~mm})\end{array}$ & $\begin{array}{l}r_{0}{ }^{\mathrm{a}} \\
(\mathrm{mm})\end{array}$ & $\begin{array}{l}b_{1} \\
(\mathrm{~mm})\end{array}$ & $\begin{array}{l}h_{1} \\
(\mathrm{~mm})\end{array}$ & $\begin{array}{l}t_{1} \\
(\mathrm{~mm})\end{array}$ & $\begin{array}{l}r_{1}^{\mathrm{a}} \\
(\mathrm{mm})\end{array}$ & $\begin{array}{l}\Delta{\text { (left })^{b}}_{(\mathrm{mm})}\end{array}$ & $\begin{array}{l}\Delta{\text { (right })^{b}}_{(\mathrm{mm})}\end{array}$ & $\begin{array}{l}f_{y} \\
(\mathrm{MPa})\end{array}$ & $\begin{array}{l}f_{u} \\
(\mathrm{MPa})\end{array}$ \\
\hline $\mathrm{X} 1$ & $100 \times 100 \times 3$ & $100 \times 100 \times 3$ & 100.27 & 100.52 & 2.92 & 6.2 & 100.22 & 100.33 & 2.73 & 6.2 & -0.05 & -0.05 & 330 & 388 \\
\hline $\mathrm{X} 2$ & $100 \times 100 \times 4$ & $100 \times 100 \times 4$ & 100.14 & 100.36 & 3.84 & 11.5 & 100.37 & 100.19 & 3.69 & 11.5 & -0.05 & -0.30 & 330 & 404 \\
\hline $\mathrm{X} 3$ & $100 \times 100 \times 5$ & $100 \times 100 \times 5$ & 99.80 & 100.25 & 4.89 & 12.7 & 100.08 & 99.90 & 4.70 & 12.7 & -0.20 & -0.10 & 400 & 437 \\
\hline $\mathrm{X} 4$ & $100 \times 100 \times 6$ & $100 \times 100 \times 6$ & 99.61 & 99.63 & 5.80 & 12.1 & 99.76 & 99.66 & 5.46 & 12.1 & -0.05 & -0.20 & 370 & 425 \\
\hline $\mathrm{X} 5$ & $100 \times 100 \times 8$ & $100 \times 100 \times 8$ & 99.70 & 99.89 & 7.92 & 15.1 & 100.12 & 99.64 & 7.68 & 15.1 & -0.15 & -0.15 & 345 & 392 \\
\hline X6 & $250 \times 150 \times 5$ & $150 \times 150 \times 5$ & 250.00 & 149.77 & 5.00 & 17.7 & 150.10 & 150.10 & 4.76 & 11.4 & 3.0 & 2.0 & 463 & 513 \\
\hline $\mathrm{X} 7$ & $150 \times 150 \times 6$ & $150 \times 150 \times 6$ & 150.18 & 150.23 & 5.86 & 14.1 & 150.48 & 150.35 & 5.86 & 14.7 & -1.0 & -1.0 & 451 & 502 \\
\hline $\mathrm{X} 8$ & $350 \times 250 \times 10$ & $250 \times 250 \times 10$ & 350.40 & 250.70 & 9.94 & 27.0 & 248.50 & 249.00 & 9.94 & 26.6 & 0.0 & 0.0 & 468 & 534 \\
\hline X9 & $400 \times 300 \times 8$ & $300 \times 300 \times 8$ & 400.00 & 300.00 & 7.92 & 22.7 & 300.30 & 300.30 & 7.97 & 22.3 & 2.0 & 2.0 & 481 & 546 \\
\hline
\end{tabular}

${ }^{\mathrm{a}} \mathrm{r}=$ outside corner radius

b $\Delta$ is the imperfection of the chord side wall at the vertical centre line of the connection, positive when measured outwards.

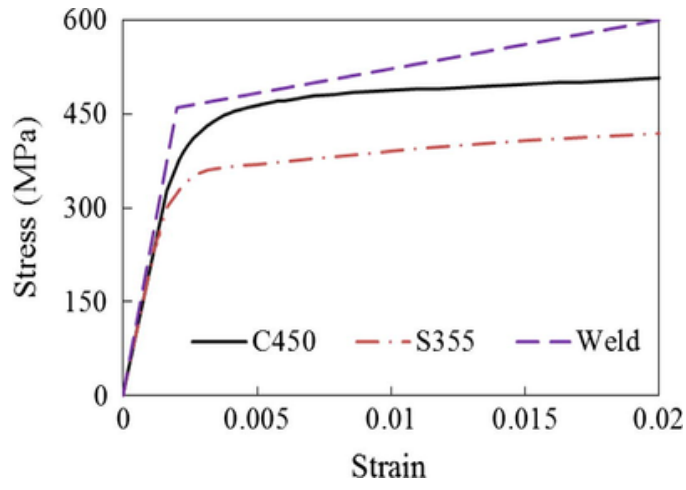

Fig. 3. Stress-strain curves.

ering mesh sizes ranging from $2 \mathrm{~mm}$ to $15 \mathrm{~mm}$ (in the most refined region), 8-node as well as 20-node hexahedral elements, and 'General Static' vs. 'Riks' analyses. The peak load $P_{u l t}$, the axial shortening $d$ at the peak load $P_{u l t}$ and the initial stiffness $K_{i}$ obtained from the models are compared in Table 2. Fig. 5 also plots the peak load $P_{u l t}$ as a function of the mesh size. It was found that the results are quite insensitive to either the mesh size or the number of nodes in the element, as long as the mesh size is smaller than the chord wall thickness in the most refined region. However, a 20-node quadratic hexahedral element significantly increased the running time and was therefore not used in further analyses. Nevertheless, quadratic tetrahedral elements were adopted in the welds in all cases due to the occasionally high aspect ratios of these elements. A 'Riks' analysis did not deliver results which were significantly different from a 'General Static' analysis, and the Riks solver was selected because of its computational efficiency.

The FE results for all nine tests $\mathrm{X} 1-\mathrm{X} 9$ are compared to the experimental data in Table 3 with respect to the ultimate load $P_{u l t}$, the initial stiffness $K_{i}$ and the axial shortening $d$ at the peak load. Good agreement was generally achieved between the FE models and the test data. The average ratio of the FE predicted capacity to the measured capacity $\left(P_{u l t, F E A} / P_{u l t, t e s t}\right)$ was found to be 1.03 with a standard deviation of 0.1 . Note that a comparison of the peak load for X8 was not included, because the peak load was not reached in the actual test.

To further illustrate the predictive capacity of the FE models, Fig. 6 shows the failure modes of specimen X1 obtained from both the experiment and the FE model, while Fig. 7 compares the predicted and

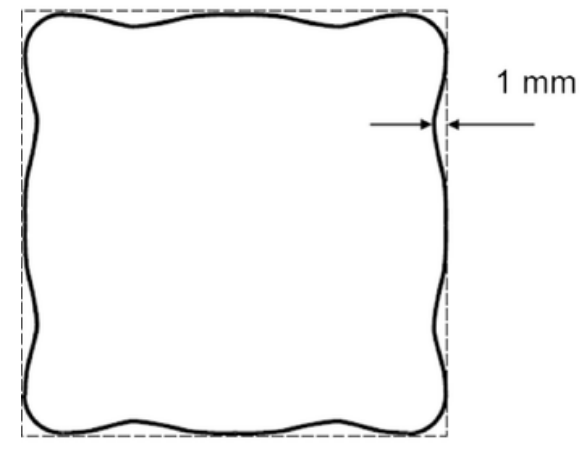

(a) Measured chord imperfection

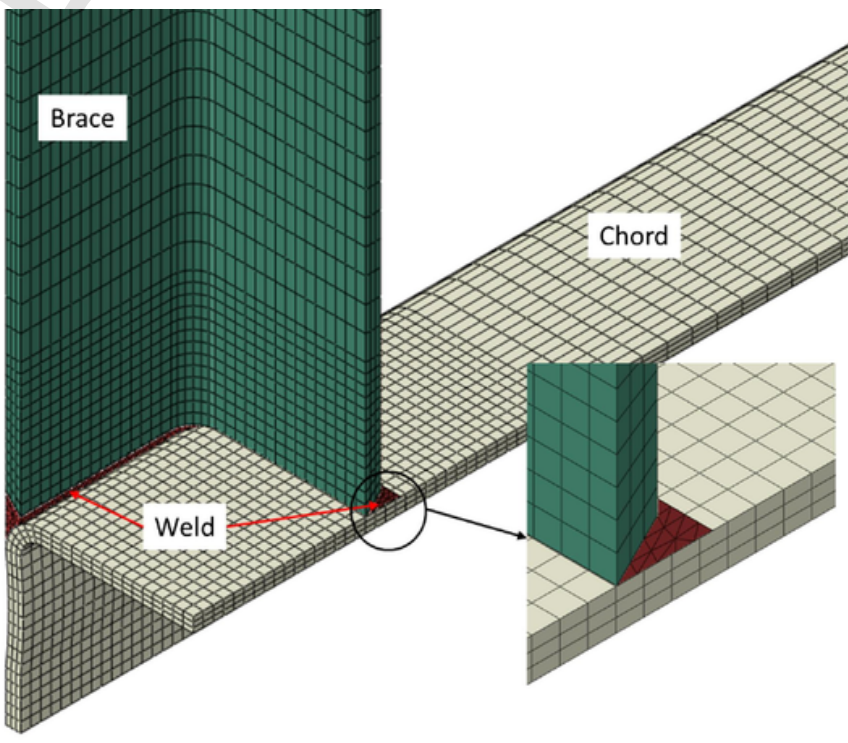

(b) Finite element mesh

Fig. 4. Finite element model of test $\mathrm{X} 7$ 
Table 2

Sensitivity studies.

\begin{tabular}{lllllll}
\hline Label & $\begin{array}{l}\text { Element } \\
\text { type }\end{array}$ & $\begin{array}{l}\text { Analysis } \\
\text { solver }\end{array}$ & $\begin{array}{l}\text { Mesh size } \\
(\mathrm{mm})\end{array}$ & $\begin{array}{l}P_{\text {ult }} \\
(\mathrm{kN})\end{array}$ & $\begin{array}{l}d \\
(\mathrm{~mm})\end{array}$ & $\begin{array}{l}K_{i}(\mathrm{kN} / \\
\mathrm{mm})\end{array}$ \\
\hline Test & & & & 832.35 & 2.68 & 353 \\
S1 & Hex-8 & Riks & 2 & 860.42 & 3.03 & 356 \\
S2 & Hex-8 & Riks & 3 & 860.42 & 3.05 & 356 \\
S3 & Hex-8 & Riks & 4 & 859.90 & 3.05 & 355 \\
S4 & Hex-20 & Riks & 4 & 888.62 & 3.15 & 356 \\
S5 & Hex-8 & Static & 4 & 859.30 & 3.02 & 353 \\
S6 & Hex-8 & Riks & 5 & 858.80 & 3.02 & 355 \\
S7 & Hex-8 & Riks & 6 & 865.82 & 3.07 & 354 \\
S8 & Hex-8 & Riks & 8 & 888.62 & 3.15 & 353 \\
S9 & Hex-8 & Riks & 10 & 826.89 & 3.22 & 347 \\
S10 & Hex-8 & Riks & 15 & 998.11 & 4.62 & 351 \\
\hline
\end{tabular}

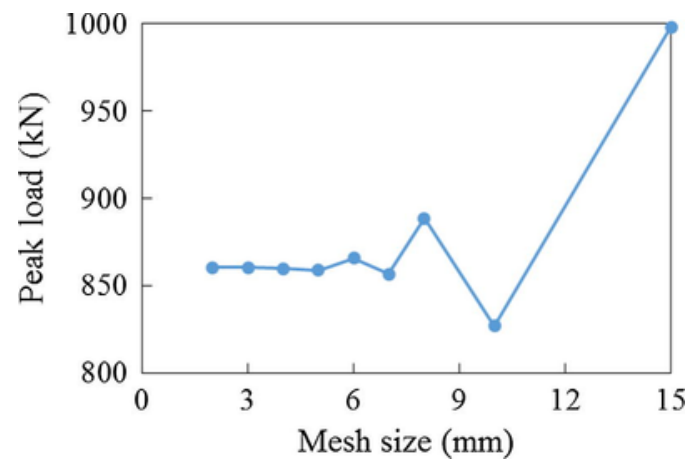

Fig. 5. Effect of mesh size.

Table 3

FE model validation.

\begin{tabular}{|c|c|c|c|c|c|c|c|c|c|}
\hline \multirow[t]{2}{*}{ Label } & \multicolumn{3}{|c|}{ Ultimate load, $P_{u l t}(\mathrm{kN})$} & \multicolumn{3}{|c|}{$\begin{array}{l}\text { Initial stiffness, } K_{i}(\mathrm{kN} / \\
\mathrm{mm})\end{array}$} & \multicolumn{3}{|c|}{$\begin{array}{l}\text { Axial shortening, } d \\
(\mathrm{~mm})\end{array}$} \\
\hline & Test & FEA & $\begin{array}{l}\text { FEA/ } \\
\text { test }\end{array}$ & Test & FEA & FEA/test & Test & FEA & $\begin{array}{l}\text { FEA } \\
\text { test }\end{array}$ \\
\hline $\mathrm{X} 1$ & 176 & 182 & 1.03 & 208 & 233 & 1.12 & 0.92 & 0.9 & 0.98 \\
\hline $\mathrm{X} 2$ & 302 & 270 & 0.89 & 229 & 312 & 1.36 & 1.6 & 1.03 & 0.64 \\
\hline $\mathrm{X} 3$ & 373 & 434 & 1.16 & 291 & 392 & 1.35 & 1.75 & 1.68 & 0.96 \\
\hline $\mathrm{X} 4$ & 560 & 501 & 0.89 & 369 & 458 & 1.24 & 2.46 & 1.69 & 0.69 \\
\hline $\mathrm{X} 5$ & 783 & 789 & 1.01 & 459 & 624 & 1.36 & 4.03 & 3.87 & 0.96 \\
\hline X6 & 409 & 448 & 1.09 & 271 & 252 & 0.93 & 5.07 & 2.55 & 0.50 \\
\hline $\mathrm{X} 7$ & 828 & 862 & 1.04 & 411 & 373 & 0.91 & 2.65 & 3.02 & 1.14 \\
\hline $\mathrm{X} 8$ & - & 2045 & - & 810 & 737 & 0.91 & - & 3.64 & - \\
\hline \multirow[t]{3}{*}{ X9 } & 1289 & 1405 & 1.09 & 870 & 698 & 0.80 & 2.22 & 3.54 & 1.59 \\
\hline & & Avg. & 1.03 & & Avg. & 1.11 & & Avg. & 0.93 \\
\hline & & $\begin{array}{l}\text { St. } \\
\text { dev. }\end{array}$ & 0.1 & & $\begin{array}{l}\text { St. } \\
\text { dev. }\end{array}$ & 0.23 & & $\begin{array}{l}\text { St. } \\
\text { dev. }\end{array}$ & 0.34 \\
\hline
\end{tabular}

the measured load vs. axial shortening curve and load vs. side wall deflection curve of specimen X1.

After verifying the FE model, a total of 36 parametric studies were run to investigate the effect of an added compressive chord pre-load. Three levels of pre-compression were applied to X1-X9, amounting to $25 \%, 50 \%$ and $75 \%$ of the chord squash load. A 'General Static' step was first used to apply the chord compression, followed by a 'Riks' step with increasing brace compression while keeping the chord load constant.

As an example, Fig. 8 shows the load-axial shortening curves of joints $\mathrm{X} 1$ and $\mathrm{X} 5$, subject to various levels of chord pre-load. It is seen that the chord pre-load has only a very minor effect on the ultimate capacity and behaviour of joint X1, which initially buckles in the elastic range. This is consistent with the work previously conducted by Platt [17]. However the compressive chord pre-load results in a more substantial effect on the ultimate capacity when joint X5 is considered, where initial buckling is interwoven with gradual material yielding. Interestingly, X5 maintains its stiffness longer (i.e. at higher load levels) when a higher compressive force is present in the chord. This can be attributed to the state of biaxial compression in the side wall which postpones material yielding until higher stress levels. However, the peak load of the X-joint is gradually reduced with increasing chord pre-load, as the post-buckling reserve capacity of the side wall is significantly reduced by the bi-axially applied load.

The proposed design methodology follows the rationale put forward in $[5,6]$ that initial buckling of the side wall is the limiting factor in the determination of the joint capacity. This is based on the need to avoid non-linear interaction effects between flexural bucking of the members and local buckling of the joint.

The side wall buckling loads determined from all FE models are listed in Table 4. The exact point of buckling is not always easy to pinpoint from the change in axial stiffness of the specimen or the lateral side wall displacements, especially when buckling takes place in the inelastic range. The buckling load was therefore determined from the divergence point between a geometric non-linear analysis and a linear analysis (both including material non-linearity) in the load vs. axial shortening diagram (see Fig. 9). It is also noted that no results are provided in Table 4 for X6, X8 and X9 at elevated levels of chord pre-load, since these slender chord sections simply cannot sustain these compressive pre-loads and would collapse in local buckling even before any brace load is applied.

It is seen from Table 4 that, in general, the chord pre-load does not have a major effect on the buckling load. Only the very slender side walls $\left(\mathrm{h}_{0} / \mathrm{t}_{0}=50\right)$ show a distinct reduction in buck-ling load. Interestingly, a slight increase in buckling load is typically observed in the stockiest sections, which buckle inelastically. As previously discussed in relation to Fig. 8, this can be attributed to the state of biaxial compression in the side wall actually delaying yielding.

\section{Proposed design method}

Table 4 lists, for each specimen: the elastic critical buckling load $P_{c r}$ obtained using Eq. (24), the inelastic buckling load $P_{b, F E A}$, and the yield load $P_{y}$, which is taken as:

$$
P_{y}=1.2 \times 2 f_{y} h_{1} t=2.4 f_{y} h_{1} t
$$

The factor 1.2 thereby takes into account that some of the load follows an alternative load path through the chord top and bottom faces and then spreads out into the chord side walls. This factor agrees well with the failure load observed in the stockiest joint (X5) and is slightly conservative based on experimental results and equations provided in $[3,9]$. A dimensionless slenderness parameter $\lambda$ can then be defined as:

$$
\lambda=\sqrt{\frac{P_{y}}{P_{c r}}}
$$

The dimensionless buckling loads $\chi=\mathrm{P}_{\mathrm{b}, \mathrm{FEA}} / \mathrm{P}_{\mathrm{y}}$ at different chord pre-load levels, obtained from all FE models, are plotted against the calculated slenderness values $\lambda$ in Fig. 10, which also shows the elastic critical buckling curve in dashed line: 


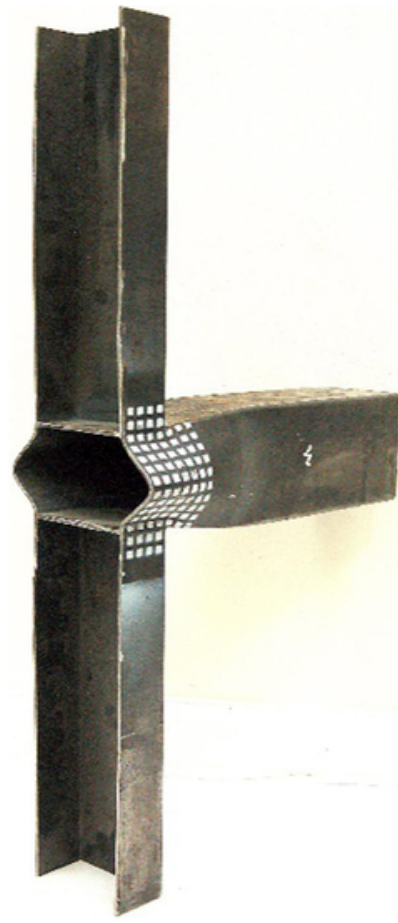

(a) Failure mode inexperiment (half specimen)
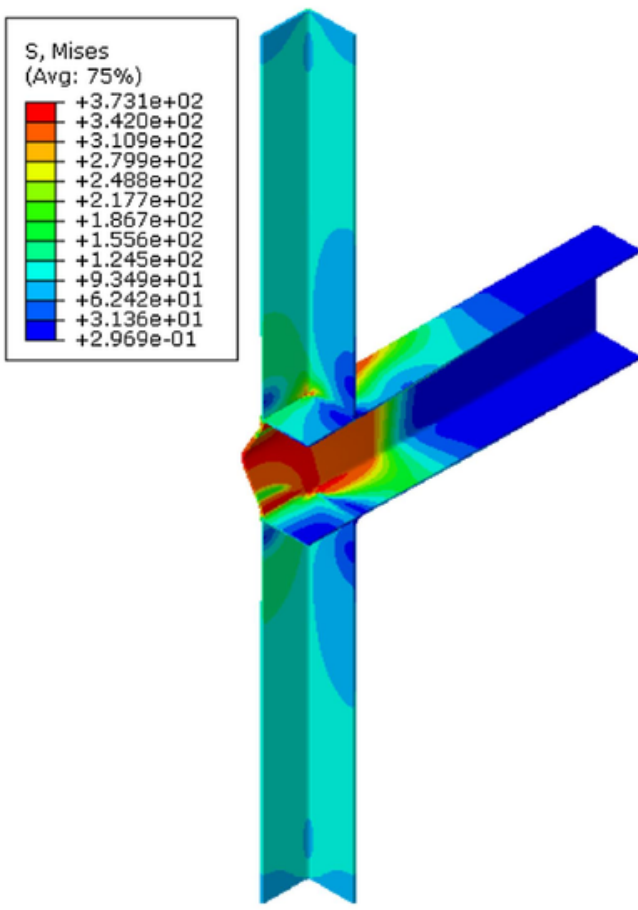

(b) Failure mode in FEA (quarter model)

Fig. 6. Comparison of experimental and predicted failure modes of test specimen X1.

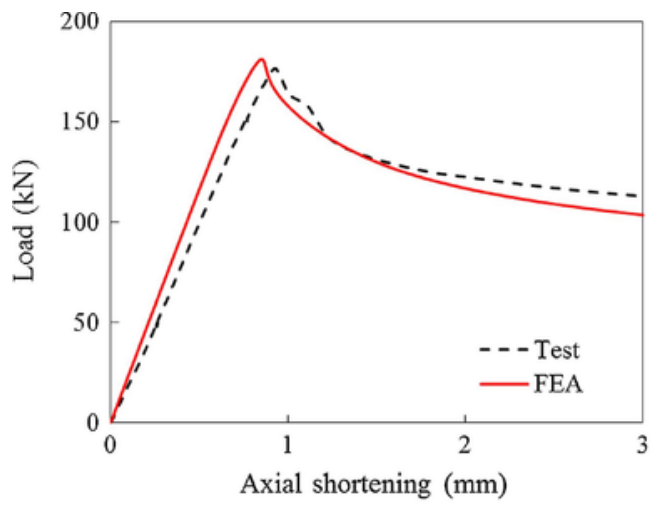

(a) Load-axial shortening curve

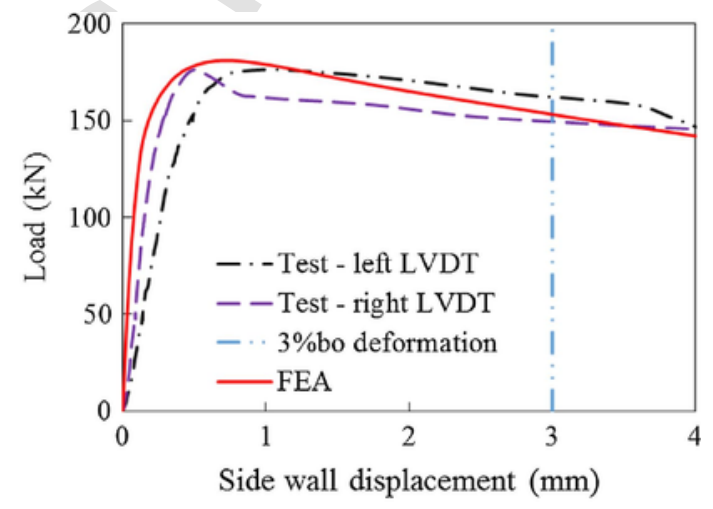

(b) Load-side wall deflection curve

Fig. 7. Comparison of experimental and predicted behaviour of test specimen X1.

$\chi=\frac{P_{c r}}{P_{y}}=\frac{1}{\lambda^{2}}$

It is seen that, generally, a good agreement is obtained between the data and the above equation in the elastic range $(\lambda>>1)$. In order to account for the gradual transition from the elastic to the inelastic buckling range at lower slenderness values, the following equation is proposed (denoted as 'Prediction 1'), which is deliberately aligned with the current CIDECT practice of referring to the code specifications for column buckling (e.g. EN1993-1-1 [18]):

$$
P_{b}=\chi P_{y}
$$

with:

$$
\begin{aligned}
& \chi=\frac{1}{\phi+\sqrt{\phi^{2}-\lambda^{2}}} \leqslant 1.0 \\
& \phi=\frac{1}{2}\left[1+\alpha(\lambda-0.2)+\lambda^{2}\right]
\end{aligned}
$$




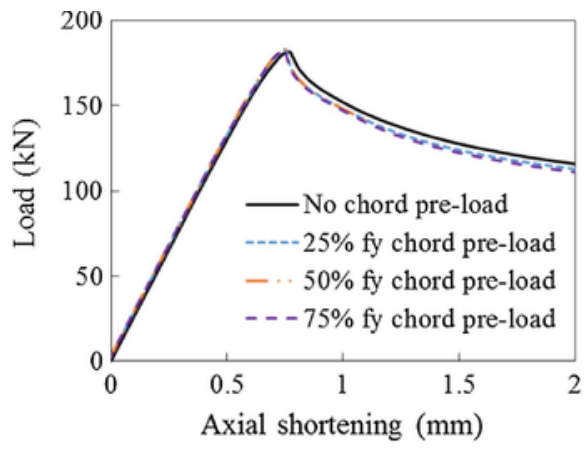

(a) $\mathrm{X} 1$

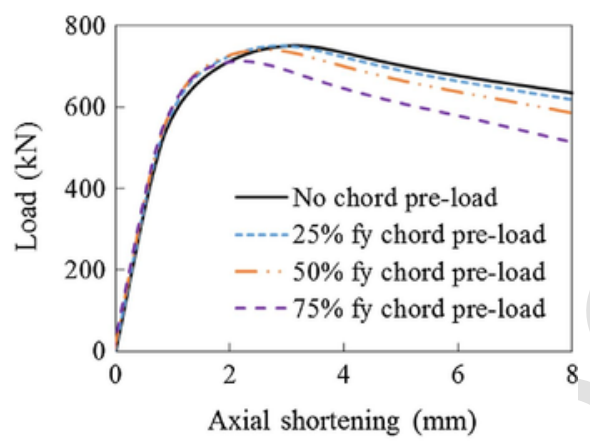

(b) X5

Fig. 8. Effect of compressive chord pre-load on load-axial shortening relationship.

Table 4

Test results and predicted capacities.

\begin{tabular}{|c|c|c|c|c|c|c|c|c|c|c|c|c|c|c|}
\hline Test & $\mathrm{h}_{0} / \mathrm{t}_{0}$ & $\begin{array}{l}\text { Pre-load } \\
\text { level }(\%)\end{array}$ & $\begin{array}{l}\mathrm{Py} \\
(\mathrm{kN})\end{array}$ & $\begin{array}{l}\mathrm{P}_{\mathrm{b}, \mathrm{FEA}} \\
(\mathrm{kN})\end{array}$ & $\begin{array}{l}\mathrm{P}_{\mathrm{cr}} \\
(\mathrm{kN})\end{array}$ & $\begin{array}{l}\lambda_{\text {pred,1 }} \\
(-)\end{array}$ & $\begin{array}{l}\mathrm{P}_{\mathrm{d}, \mathrm{CIDECT}} \\
(\mathrm{kN})\end{array}$ & $\begin{array}{l}\mathrm{P}_{\mathrm{ult}, \mathrm{CIDECT}} \\
(\mathrm{kN})\end{array}$ & $\begin{array}{l}\mathrm{P}_{\text {pred, } 1} \\
(\mathrm{kN})\end{array}$ & $\begin{array}{l}\mathrm{P}_{\text {pred,2 }} \\
(\mathrm{kN})\end{array}$ & $\begin{array}{l}\mathrm{Pb}, \mathrm{FEA} / \mathrm{Py} \\
(-)\end{array}$ & $\begin{array}{l}\mathrm{P}_{\text {ult,CIDECT }} / \mathrm{P}_{\mathrm{b}, \mathrm{FEA}} \\
(-)\end{array}$ & $\begin{array}{l}\mathrm{P}_{\text {pred }, 1} / \mathrm{P}_{\mathrm{b}, \mathrm{FEA}} \\
(-)\end{array}$ & $\begin{array}{l}\mathrm{P}_{\text {pred }, 2} / \mathrm{P}_{\mathrm{b}, \text { FEA }} \\
(-)\end{array}$ \\
\hline \multirow[t]{4}{*}{$\mathrm{X} 1$} & \multirow[t]{4}{*}{36.7} & 0 & 232 & 170 & 125 & 1.36 & 61 & 76 & 114 & 114 & 0.73 & 0.45 & 0.67 & 0.67 \\
\hline & & 25 & 232 & 168 & 116 & 1.41 & 59 & 74 & 106 & 114 & 0.72 & 0.44 & 0.63 & 0.68 \\
\hline & & 50 & 232 & 168 & 106 & 1.48 & 57 & 71 & 98 & 114 & 0.72 & 0.42 & 0.58 & 0.68 \\
\hline & & 75 & 232 & 168 & 95 & 1.56 & 53 & 66 & 89 & 114 & 0.72 & 0.39 & 0.53 & 0.68 \\
\hline \multirow[t]{4}{*}{$\mathrm{X} 2$} & \multirow[t]{4}{*}{26.7} & 0 & 305 & 277 & 285 & 1.03 & 122 & 153 & 228 & 228 & 0.91 & 0.55 & 0.82 & 0.82 \\
\hline & & 25 & 305 & 286 & 272 & 1.06 & 119 & 149 & 222 & 228 & 0.94 & 0.52 & 0.78 & 0.80 \\
\hline & & 50 & 305 & 286 & 259 & 1.08 & 114 & 143 & 215 & 228 & 0.94 & 0.50 & 0.75 & 0.80 \\
\hline & & 75 & 305 & 286 & 246 & 1.11 & 107 & 133 & 208 & 228 & 0.94 & 0.47 & 0.73 & 0.80 \\
\hline \multirow[t]{4}{*}{$\mathrm{X} 3$} & \multirow[t]{4}{*}{21.2} & 0 & 469 & 386 & 594 & 0.89 & 236 & 295 & 401 & 401 & 0.82 & 0.76 & 1.04 & 1.04 \\
\hline & & 25 & 469 & 400 & 575 & 0.90 & 229 & 286 & 397 & 401 & 0.85 & 0.72 & 0.99 & 1.00 \\
\hline & & 50 & 469 & 399 & 555 & 0.92 & 220 & 275 & 392 & 401 & 0.85 & 0.69 & 0.98 & 1.00 \\
\hline & & 75 & 469 & 399 & 535 & 0.94 & 205 & 256 & 387 & 401 & 0.85 & 0.64 & 0.97 & 1.00 \\
\hline \multirow[t]{4}{*}{$\mathrm{X} 4$} & \multirow[t]{4}{*}{18.1} & 0 & 513 & 477 & 995 & 0.72 & 319 & 399 & 475 & 475 & 0.93 & 0.84 & 1.00 & 1.00 \\
\hline & & 25 & 513 & 482 & 974 & 0.73 & 310 & 387 & 474 & 475 & 0.94 & 0.80 & 0.98 & 0.99 \\
\hline & & 50 & 513 & 483 & 953 & 0.73 & 298 & 372 & 473 & 475 & 0.94 & 0.77 & 0.98 & 0.98 \\
\hline & & 75 & 513 & 484 & 932 & 0.74 & 278 & 347 & 472 & 475 & 0.94 & 0.72 & 0.97 & 0.98 \\
\hline \multirow[t]{4}{*}{ X5 } & \multirow[t]{4}{*}{12.9} & 0 & 654 & 672 & 2465 & 0.52 & 520 & 649 & 632 & 632 & 1.03 & 0.97 & 0.94 & 0.94 \\
\hline & & 25 & 654 & 683 & 2438 & 0.52 & 505 & 631 & 632 & 632 & 1.04 & 0.92 & 0.93 & 0.93 \\
\hline & & 50 & 654 & 683 & 2411 & 0.52 & 485 & 606 & 632 & 632 & 1.04 & 0.89 & 0.93 & 0.93 \\
\hline & & 75 & 654 & 666 & 2384 & 0.52 & 452 & 565 & 632 & 632 & 1.02 & 0.85 & 0.95 & 0.95 \\
\hline \multirow[t]{4}{*}{ X6 } & \multirow[t]{4}{*}{50.0} & 0 & 834 & 270 & 243 & 1.85 & 75 & 104 & 231 & 231 & 0.32 & 0.39 & 0.86 & 0.86 \\
\hline & & 25 & 834 & 213 & 183 & 2.14 & 73 & 101 & 175 & 231 & 0.26 & 0.47 & 0.82 & 1.08 \\
\hline & & 50 & - & - & - & - & - & - & - & - & - & - & - & - \\
\hline & & 75 & - & - & - & - & - & - & - & - & - & - & - & - \\
\hline \multirow[t]{4}{*}{$\mathrm{X} 7$} & \multirow[t]{4}{*}{25.6} & 0 & 953 & 791 & 652 & 1.21 & 285 & 396 & 573 & 573 & 0.83 & 0.50 & 0.72 & 0.72 \\
\hline & & 25 & 953 & 801 & 613 & 1.25 & 277 & 385 & 544 & 573 & 0.84 & 0.48 & 0.68 & 0.72 \\
\hline & & 50 & 953 & 781 & 572 & 1.29 & 266 & 369 & 514 & 573 & 0.82 & 0.47 & 0.66 & 0.73 \\
\hline & & 75 & 953 & 751 & 530 & 1.34 & 248 & 345 & 481 & 573 & 0.79 & 0.46 & 0.64 & 0.76 \\
\hline \multirow[t]{4}{*}{ X8 } & \multirow[t]{4}{*}{35.3} & 0 & 2778 & 1550 & 1364 & 1.43 & 482 & 669 & 1254 & 1254 & 0.56 & 0.43 & 0.81 & 0.81 \\
\hline & & 25 & 2778 & 1490 & 1199 & 1.52 & 468 & 650 & 1114 & 1254 & 0.54 & 0.44 & 0.75 & 0.84 \\
\hline & & 50 & 2778 & 1410 & 1024 & 1.65 & 450 & 624 & 961 & 1254 & 0.51 & 0.44 & 0.68 & 0.89 \\
\hline & & 75 & - & - & - & - & - & - & - & - & - & - & - & - \\
\hline \multirow[t]{7}{*}{ X9 } & \multirow[t]{7}{*}{50.5} & 0 & 2745 & 682 & 604 & 2.13 & 227 & 315 & 579 & 579 & 0.25 & 0.46 & 0.85 & 0.85 \\
\hline & & 25 & 2745 & 590 & 445 & 2.48 & 221 & 306 & 430 & 579 & 0.21 & 0.52 & 0.73 & 0.98 \\
\hline & & 50 & - & - & - & - & - & - & - & - & - & - & - & - \\
\hline & & 75 & - & - & - & & - & - & - & - & - & - & - & - \\
\hline & & & & & & & & & & & Avg. & 0.59 & 0.82 & 0.87 \\
\hline & & & & & & & & & & & St. dev. & 0.18 & 0.14 & 0.12 \\
\hline & & & & & & & & & & & $\mathrm{COV}$ & 0.30 & 0.18 & 0.14 \\
\hline
\end{tabular}

where $P_{y}$ and $\lambda$ are determined by Eqs. (27) and (28), respectively. By trial and error the value of the imperfection factor $\alpha$ was determined to be 0.08 , as this results in an accurate yet conservative fit of the data. It is seen in Fig. 10 that the proposed equation agrees well with the numerically determined buckling loads $P_{b, F E A}$, both for slender side walls buckling elastically and stocky side walls buckling inelastically, although it leads to somewhat conservative results in the intermediate slenderness range. Eq. (30) is also consistent with the equation provided in $[6]$ in the absence of a chord load. The buckling resistances predicted by the above equations are listed as $P_{\text {pred }, 1}$ in Table 4

In light of the observation that the buckling loads do not vary all that significantly with different levels of chord pre-load (see Table 4), it is worth investigating whether the effect of the chord pre-load can simply be ignored in design. With $a=0$ in Eq. (22), the methodology 


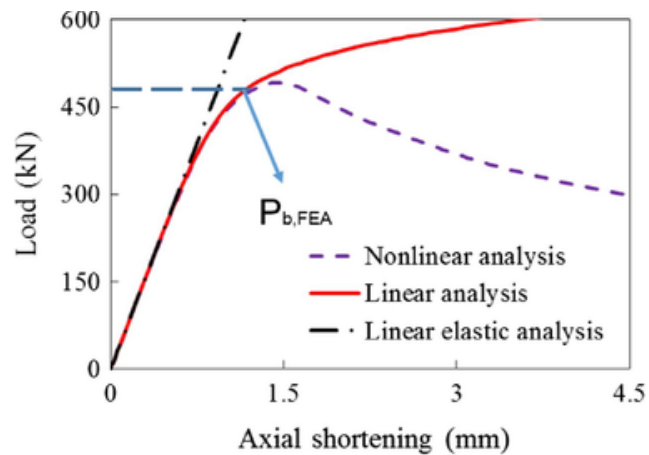

(a) No chord pre-load

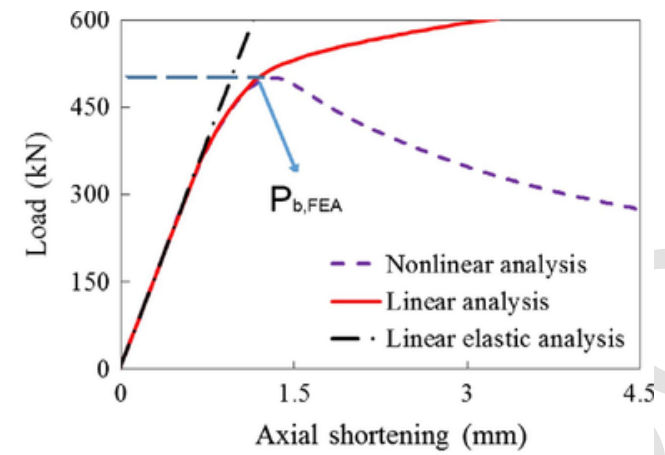

(b) $50 \%$ chord pre-load

Fig. 9. Determination of the buckling load of specimen X4.

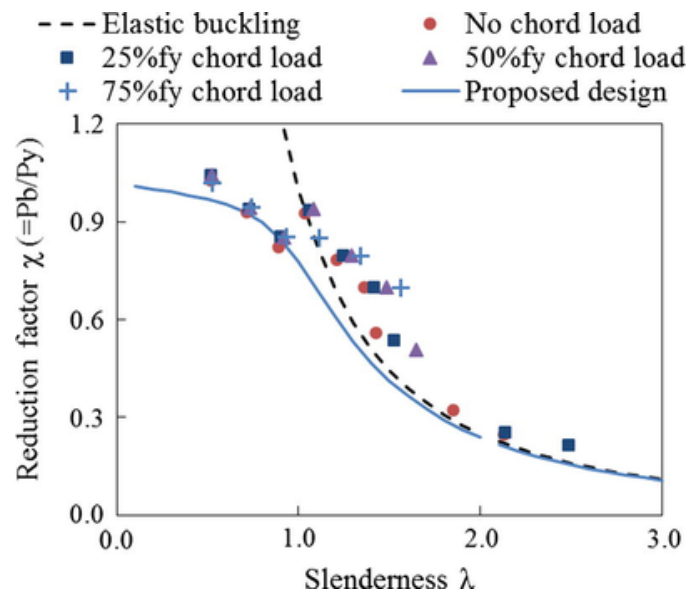

Fig. 10. Buckling loads at different chord pre-load levels and proposed design method 1.

reduces to the one previously proposed in [6] (from here on referred to as 'Prediction 2'). The corresponding buckling resistances $P_{\text {pred,2 }}$ predicted for all numerical simulations are also listed in Table 4 . The full design curve is presented in Fig. 11. Good agreement with the numerical data is observed. It is even noted that much of the conservatism in the intermediate slenderness has disappeared. However, the
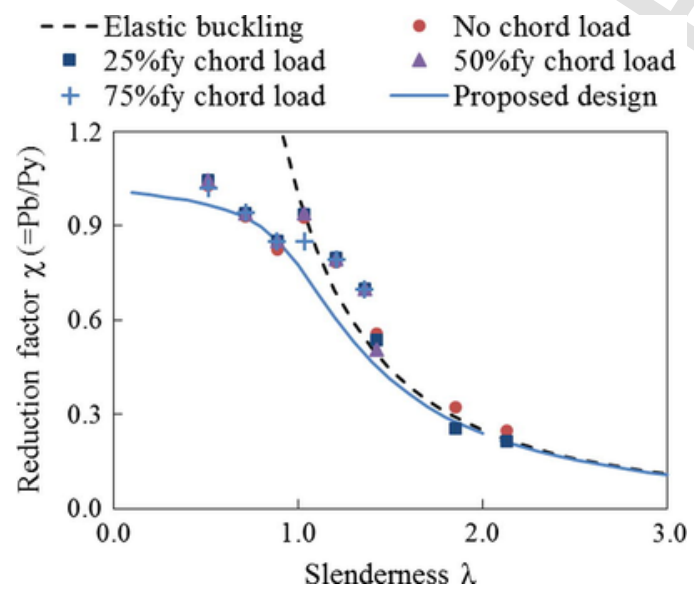

Fig. 11. Proposed design method 2. predictions are now occasionally slightly unsafe in the high slenderness range, with the buckling load being overestimated by $8 \%$ for X6 $\left(\mathrm{h}_{0} / \mathrm{t}_{0}=50\right)$ with a chord pre-load of $25 \%$ of the squash load.

Table 4 also lists the ratios of the predicted buckling capacities over the numerical results, using the current CIDECT rules, as well as Prediction 1 (Fig. 10) and Prediction 2 (Fig. 11). An average ratio of 0.82 with a standard deviation of 0.14 was obtained for Prediction 1 , while an average ratio of 0.87 with a standard deviation of 0.12 was achieved for Prediction 2. In order to compare the performance of the proposed design equations with that of the current CIDECT rules, it should be noted that the CIDECT equations provide factored design resistances, i.e. they already contain an implicit safety factor, which is $\gamma_{M}=1.25$ for side wall buckling $[11,12]$. This safety factor is implemented through the use of a reduction factor of 0.8 in the CIDECT equation for the side wall buckling stress $f_{k}[2]$. Also, the CIDECT rules impose an extra reduction factor of 0.9 on the capacity of the higher grade $\mathrm{C} 450$ connections (applicable to X6-X9) [2]. In order to allow an objective comparison, the CIDECT predicted design resistances $\mathrm{P}_{\mathrm{d}, \mathrm{CIDECT}}$ in Table 4 were first transformed into 'nominal' resistances $\mathrm{P}_{\text {ult,CIDECT }}$, by dividing away the safety factor of 0.8 and, where applicable, the extra reduction factor of 0.9 . It is seen that both proposed methodologies strongly outperform the current CIDECT design rule for side wall buckling, which over the same data set features an average ratio of the predicted to the FE capacity of 0.59 with a standard deviation of 0.18 . Importantly, it is also seen that the CIDECT rule does not offer a consistent margin of safety, but is more conservative for side walls with high $h_{0} / t_{0}$ values. In this respect, it should also be noted that the applicability of the current CIDECT rule is limited to an $h_{0} / t_{0}$ ratio of 40 , while the proposed equations are based on data including sections with $h_{0} / t_{0}$ ratios of up to 50 .

\section{Reliability analysis}

In this section of the paper, the reliability of the two proposed design models is assessed within the frameworks of both the Eurocode $[19]$ and the AISC specifications [20].

In the Eurocode, the limit state function $\mathrm{Z}$ is defined as:

$$
Z=K_{R} R-K_{E}(G+Q)
$$

or, according to an alternative definition, which will be used in this paper, as: 


$$
Z=\frac{K_{R} R}{K_{E}}-(G+Q)
$$

In the above equation $K_{R}$ is the model uncertainty of the resistance $R$ and $K_{E}$ is the model uncertainty of the $(G+Q)$ load effects, where $G$ and $Q$ denote the dead and the live load, respectively. The probability of failure $P_{f}$ can then be evaluated using:

$$
P_{f}=P(Z \leqslant 0)=P\left(\left(\frac{K_{R} R}{K_{E}}-(G+Q)\right) \leqslant 0\right)=\Phi(-\beta)
$$

where $\beta$ is the reliability index and $\Phi$ is the cumulative distribution function of the standard normal distribution. To ensure that the structure has an acceptable level of safety with a sufficiently small probability of failure $P_{f}$, the reliability index $\beta$ should exceed a specific target value. For new structures with a design working life of 50 years and a consequence class rated as CC2 (moderate consequences of failure), the Eurocode prescribes a reliability index of 3.8 [19]. In this paper a target value of 3.8 was therefore adopted to calibrate the partial safety factor $\gamma_{M}$.

The first order reliability method (FORM) was adopted to carry out the reliability analysis. The probabilistic models of the basic variables are listed in Table 5, based on literature data. Assuming that both the resistance and the load effects follow lognormal distributions, the resultant limit state function Z (Eq. (34)) will also follow a lognormal distribution. In this case the reliability index $\beta$ can be expressed in terms of the mean values and the coefficients of variation $(\mathrm{COV})$ of the resistance and the load effects as follows [21]:

$$
\beta=\frac{\mu_{\ln R^{\prime}}-\mu_{\ln S}}{\sqrt{\sigma_{\ln R^{\prime}}^{2}+\sigma_{\ln S}^{2}}}=\frac{\ln \left(\frac{\mu_{R^{\prime}}}{\mu_{S}} \sqrt{\frac{1+V_{S}^{2}}{1+V_{R^{\prime}}^{2}}}\right)}{\sqrt{\ln \left[\left(1+V_{R^{\prime}}^{2}\right)\left(1+V_{S}^{2}\right)\right]}}
$$

where

$$
\begin{aligned}
& R^{\prime}=\frac{K_{R} R}{K_{E}} \\
& S=G+Q
\end{aligned}
$$

and $\mu_{R^{\prime}}, \mu_{S}, V_{R^{\prime}}$ and $V_{S}$ are the mean values and COVs of the re-

Table 5

Statistical distributions used in Eurocode approach.

\begin{tabular}{llllll}
\hline Variable & Distribution & Nominal & Mean & COV & Reference \\
\hline $\mathrm{G}$ & Normal & $G_{n}$ & $G_{n}$ & 0.1 & {$[22]$} \\
$\mathrm{Q}$ & Gumbel & $Q_{n}$ & $0.6 Q_{n}$ & 0.35 & {$[22]$} \\
$\mathrm{R}$ & Lognormal & $R_{n}$ & $R_{n}$ & 0.15 & Eq. $(50)$ \\
$K_{R}$-prediction 1 & Lognormal & - & 1.24 & 0.18 & Fitted by authors \\
$K_{R}$-prediction 2 & Lognormal & - & 1.16 & 0.15 & Fitted by authors \\
$K_{E}$ & Lognormal & - & 1 & 0.1 & {$[23]$} \\
$h_{0}$ & Normal & $h_{0}$ & $h_{0}$ & 0.005 & {$[2]$} \\
$h_{1}$ & Normal & $h_{1}$ & $h_{1}$ & 0.005 & {$[2]$} \\
$t$ & Normal & $t$ & $t$ & 0.05 & {$[2]$} \\
$E$ & Normal & $E$ & $E$ & 0.03 & {$[2]$} \\
$f_{y}$ & Lognormal & $f_{y}$ & $1.18 f_{y}$ & 0.075 & {$[2]$} \\
\hline
\end{tabular}

sistance $R^{\prime}$ and the load $S$ respectively. Furthermore, $\mu_{l n R^{\prime}}, \mu_{l n S}, \sigma_{l n R^{\prime}}$ and $\sigma_{\ln S}$ are the mean values and the standard deviations of natural logarithms of the resistance $R^{\prime}$ and the load $S$.

The mean values of $R^{\prime}$ and $S$ are obtained as follows:

$$
\begin{aligned}
& \mu_{R^{\prime}}=\frac{\mu_{K R} \mu_{R}}{\mu_{K E}}=\frac{\mu_{K R}}{\mu_{K E}} R_{n} \\
& \mu_{S}=\mu_{G}+\mu_{Q}=G_{n}+0.6 Q_{n}
\end{aligned}
$$

By introducing a load ratio $\kappa=Q_{n} / G_{n}$, Eq. (40) is transformed into:

$$
\mu_{S}=G_{n}(1+0.6 \kappa)
$$

On the other hand, design is governed by:

$$
R_{d}=\frac{R_{n}}{\gamma_{M}} \geqslant R_{E d}=1.35 G_{n}+1.5 Q_{n}
$$

where $R_{d}$ is the design resistance and $R_{E d}$ is the design load effect. By setting $R_{d}=R_{E d}$ the following relationship emerges:

$$
\frac{R_{n}}{\gamma_{M}}=1.35 G_{n}+1.5 Q_{n}
$$

or

$$
\frac{R_{n}}{G_{n}}=\gamma_{M}(1.35+1.5 \kappa)
$$

The assumption that $R_{d}=R_{E d}$ corresponds to a full use of the resistance, without reserve capacity. This assumption allows an assessment of the intrinsic safety level of the design equation without making any further assumptions with regards to the specific load conditions. Rearranging Eqs. (39)-(44) leads to:

$$
\frac{\mu_{R^{\prime}}}{\mu_{S}}=\frac{\mu_{K R} \gamma_{M}(1.35+1.5 \kappa)}{\mu_{K E}(1+0.6 \kappa)}
$$

The COVs of $\mathrm{R}^{\prime}$ and $\mathrm{S}$ are given by the following expressions:

$$
\begin{aligned}
V_{S} & =\frac{\sigma_{S}}{\mu_{S}} \\
& =\frac{\sqrt{\left(V_{G} \mu_{G}\right)^{2}+\left(V_{Q} \mu_{Q}\right)^{2}}}{\mu_{G}+\mu_{Q}} \\
& =\frac{\sqrt{V_{G}^{2}+\left(V_{Q} \cdot 0.6 \kappa\right)^{2}}}{1+0.6 \kappa} \\
V_{R^{\prime}} & =\sqrt{\left(V_{K R}\right)^{2}+\left(V_{R}\right)^{2}+\left(V_{K E}\right)^{2}}
\end{aligned}
$$

Substituting Eqs. (45)-(47) in Eq. (36) eventually yields the reli- 
ability index:

$$
\beta=\frac{\ln \left\{\left[\frac{\mu_{K R}}{\mu_{K E}} \gamma_{M}(1.35+1.5 \kappa) /(1+0.6 \kappa)\right] \sqrt{\left(1+\frac{V_{G}^{2}}{(}\right.}\right.}{\sqrt{\ln \left\{\left[1+\left(V_{K R}\right)^{2}+\left(V_{R}\right)^{2}+(\right.\right.}}
$$

After rearranging the above equation, the partial safety factor $\gamma_{M}$ is obtained as:

$$
\gamma_{M}=\frac{\exp \left\{\beta \sqrt{\ln \left[\left(1+\left(V_{K R}\right)^{2}+\left(V_{R}\right)^{2}+\left(V_{I}\right.\right.\right.}\right.}{\frac{\mu_{K R}}{\mu_{K E}}\left(\frac{1.35+1.5 \kappa}{1+0.6 \kappa}\right) \sqrt{\left(1+\frac{V_{G}^{2}+V_{Q}^{2}(0.6 \kappa)^{2}}{(1+0.6 \kappa)^{2}}\right) /[1-}}
$$

In order to apply Eq. (49), the statistical data presented in Table 5, is needed. The model uncertainty $K_{R}$ considers the deviations of the design model compared to reality and its statistical parameters were determined by fitting a lognormal distribution to the ratios of the buck-

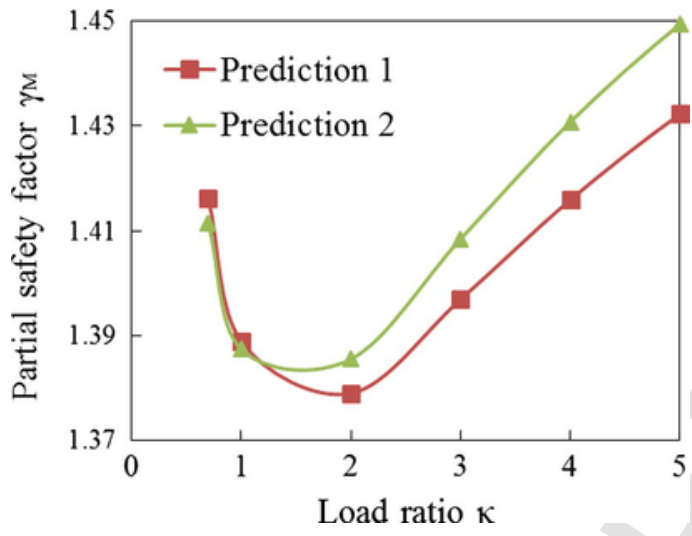

Fig. 12. Partial safety factors as a function of the live-to-dead load ratio.

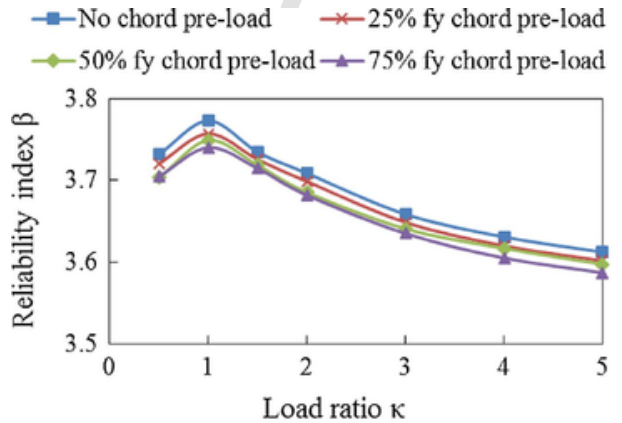

(a) Prediction 1 ling load to the model prediction $\left(P_{b, F E A} / P_{\text {pred }, 1}\right.$ or $\left.P_{b, F E A} / P_{\text {pred }, 2}\right)$. The COV of the resistance $V_{R}$ was evaluated based on a Taylor approximation of Eq. (30), while retaining the first term only:

$$
\begin{aligned}
V_{R}^{2}=\frac{1}{\left(P_{b, m}\right)^{2}}\left[\left(\frac{\partial P_{b}}{\partial h_{0}} \sigma_{h o}\right)^{2}\right. & +\left(\frac{\partial P_{b}}{\partial h_{1}} \sigma_{h 1}\right)^{2}+\left(\frac{\partial P_{b}}{\partial t} \sigma_{t}\right)^{2} \\
& \left.+\left(\frac{\partial P_{b}}{\partial E} \sigma_{E}\right)^{2}+\left(\frac{\partial P_{b}}{\partial f_{y}} \sigma_{f y}\right)^{2}\right]
\end{aligned}
$$

Using Eq. (49), the partial safety factor $\gamma_{M}$ was calculated as a function of the load ratio $\kappa$ for both Prediction 1 and Prediction 2, assuming a target reliability index of 3.8. Fig. 12 plots this relationship for both design models up to a load ratio of 5 , which is the typical range of live to dead load ratios for metal structures [24]. It is seen that, in both cases, the partial safety factor $\gamma_{M}$ displays a minimum when the load ratio is approximately equal to 2. The partial factors $\gamma_{M}$ range between 1.38 and 1.43 for Prediction 1, and between 1.38 and 1.45 for Prediction 2. To ensure that the design model achieves the required level of safety for all practical load ratios, a partial safety factor $\gamma_{M}=1.45$ is recommended for both design models.

It is noted that Eq. (36) is based on the assumption that both the resistance and the load effects follow lognormal distributions. This is not quite the case, as is seen from Table 5 and, therefore, the calculated partial safety factors are approximate. Hence, the reliability level of the two design models was more accurately assessed using Monte Carlo simulations for all nine test specimens X1-X9. The failure frequency was evaluated using:

$$
P_{f}=P_{f}\left(K_{R} R-K_{E} E<0\right)
$$

where $R$ is the resistance, calculated using the proposed design models, and $E=G+Q$ is the load effect. A Matlab [25] script was developed by the authors to create random values of the variables $h_{0}$, $h_{1}, t, E, f_{y}, K_{R}, K_{E}, G$ and $Q$ according to the distributions listed in Table 5 , in order to arrive at the distribution of $R$. Sixty million simulations were run for each joint under a given chord pre-load level and load ratio $\kappa$. Fig. 13 shows the reliability index $\beta$ obtained from the Monte-Carlo simulations for specimen X1 at various levels of chord pre-load, using a partial safety factor $\gamma_{M}=1.45$. The reliability index displays a local maximum when the load ratio $\kappa$ is approximately 1 and then decreases with increasing load ratio. It is also noted that in both design models a higher chord pre-load results in a lower reliability index. However, neither design model achieves a satisfactory

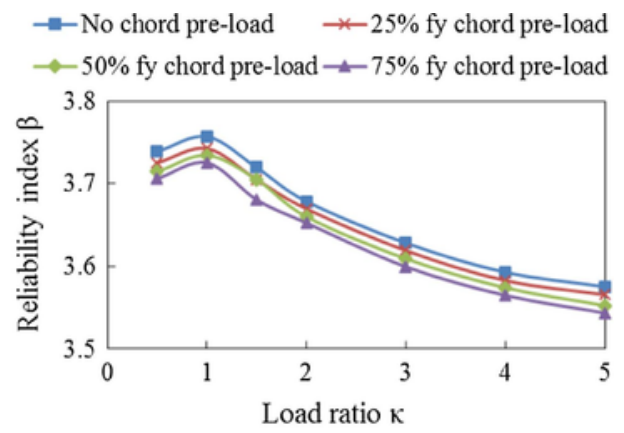

(b) Prediction 2

Fig. 13. Reliability levels of specimen X1 using $\gamma_{M}=1.45$. 
reliability level of 3.8, especially at higher load ratios. As previously pointed out, this is because neither the resistance nor the loads follow the assumed lognormal distributions. For example, it is well established that the live load Q follows a Gumbel distribution, which has a higher probability of large load values occurring than a lognormal distribution. A higher safety factor should thus be used to ensure a target reliability level of 3.8 .

Fig. 14 shows the reliability indices of specimen X1, obtained using a partial safety factor $\gamma_{M}=1.6$. Both design models now reveal a satisfactory reliability level across the various chord pre-load levels and load ratios $\kappa$.

Fig. 15 shows the reliability index for all nine test specimens using a partial safety factor $\gamma_{M}=1.6$ and $\kappa=5$. It is seen that both proposed design models provide satisfactory safety levels across all nine specimens (although Prediction 2 is minutely below the target reliability level for the most slender joints X6 and X9).

The (factored) design resistances of specimens $\mathrm{X} 1-\mathrm{X} 9$, resulting from both proposed design models, as well as the CIDECT rules, are listed in Table 6 . The proposed models consistently predict higher design resistances than the CIDECT rules, with average increases of 17\% and 26\% for Prediction 1 and Prediction 2, respectively. More importantly, the proposed design models significantly reduce the conservativeness inherent in the CIDECT rules for slender joints, while still ensuring safe predictions for the stocky joints.

With respect to the North American Standards [20], a simplified approach is usually applied when carrying out the reliability assessment, in which:

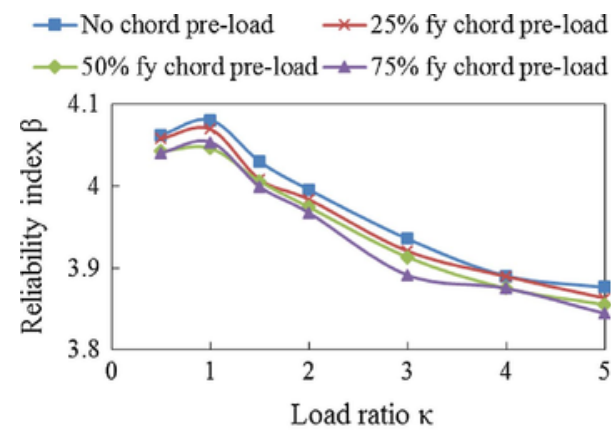

(a) Prediction 1

$$
\beta \approx \frac{\ln \left(\mu_{R} / \mu_{S}\right)}{\sqrt{V_{R}^{2}+V_{S}^{2}}}
$$

with

$$
\mu_{R}=R_{n}\left(P_{m} M_{m} F_{m}\right)
$$

and

$$
V_{R}=\sqrt{V_{P}^{2}+V_{M}^{2}+V_{F}^{2}}
$$

In the above equations, the variable $P$ denotes the ratio of the numerically determined buckling capacity to the model predictions $\left(P_{b, F E A} / P_{\text {pred }, 1}\right.$ or $\left.P_{b, F E A} / P_{\text {pred }, 2}\right)$. It plays an equivalent role to the variable $K_{R}$ in the Eurocode. The variables $M$ and $F$ denote the ratio of the actual to the nominal material properties and the ratio of the actual to the nominal cross-sectional dimensions, respectively. $P_{m}, M_{m}$ and $F_{m}$ are the mean values of $P, M$ and $F$, respectively, and $V_{P}, V_{M}$ and $V_{F}$ represent the corresponding COVs.

Compared to the Eurocode specifications, the distributions of the dead and the live loads have slightly different parameters in the North American approach, as summarized in Table 7. The design is typically governed by:

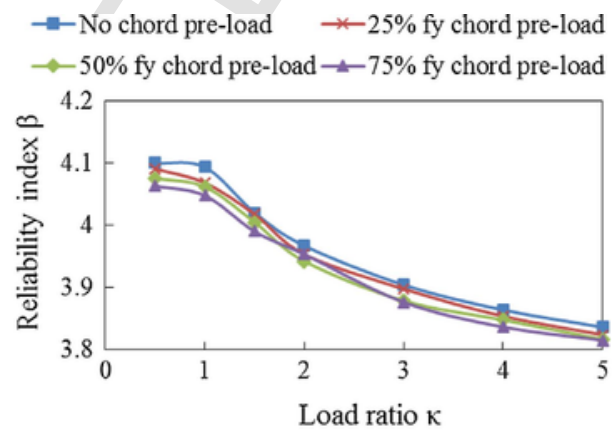

(b) Prediction 2

Fig. 14. Reliability levels of specimen X1 using $\gamma_{M}=1.6$

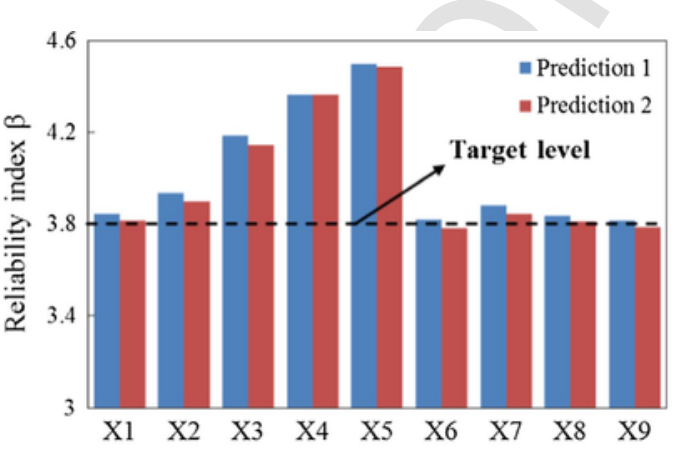

(a) No chord pre-load

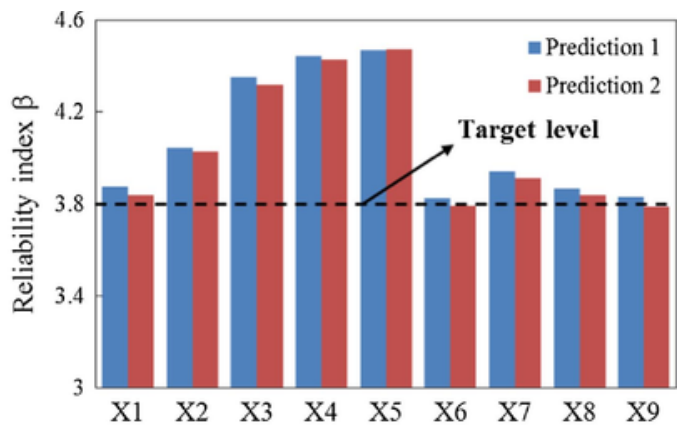

(b) $75 \%$ chord pre-load

Fig. 15. Reliability levels of all $X$-joints for a partial safety factor $\gamma_{M}=1.6$ and a load ratio $\kappa=5$. 
Table 6

Design resistances of all specimens.

\begin{tabular}{|c|c|c|c|c|c|c|c|c|c|}
\hline Label & $h_{0} / t_{0}$ & Pre-load level (\%) & Py $(\mathrm{kN})$ & $\mathrm{P}_{\mathrm{cr}}(\mathrm{kN})$ & $\mathrm{P}_{\mathrm{d}, \mathrm{CIDECT}}(\mathrm{kN})$ & $\mathrm{P}_{\mathrm{d}, \text { pred1 }}(\mathrm{kN})$ & $\mathrm{P}_{\mathrm{d}, \mathrm{pred} 2}(\mathrm{kN})$ & $\mathrm{P}_{\mathrm{d}, \text { pred } 1} / \mathrm{P}_{\mathrm{d}, \mathrm{CIDECT}}(-)$ & $\mathrm{P}_{\mathrm{d}, \text { pred2 }} / \mathrm{P}_{\mathrm{d}, \mathrm{CIDECT}}(-)$ \\
\hline \multirow[t]{4}{*}{$\mathrm{X} 1$} & 36.7 & 0 & 232 & 125 & 61 & 71 & 71 & 1.18 & 1.18 \\
\hline & & 25 & 232 & 116 & 59 & 66 & 71 & 1.13 & 1.21 \\
\hline & & 50 & 232 & 106 & 57 & 61 & 71 & 1.08 & 1.26 \\
\hline & & 75 & 232 & 95 & 53 & 56 & 71 & 1.05 & 1.35 \\
\hline \multirow[t]{4}{*}{$\mathrm{X} 2$} & 26.7 & 0 & 305 & 285 & 122 & 143 & 143 & 1.16 & 1.16 \\
\hline & & 25 & 305 & 272 & 119 & 139 & 143 & 1.17 & 1.20 \\
\hline & & 50 & 305 & 259 & 114 & 135 & 143 & 1.18 & 1.25 \\
\hline & & 75 & 305 & 246 & 107 & 130 & 143 & 1.22 & 1.34 \\
\hline \multirow[t]{4}{*}{$\mathrm{X} 3$} & 21.2 & 0 & 469 & 594 & 236 & 250 & 250 & 1.06 & 1.06 \\
\hline & & 25 & 469 & 575 & 229 & 248 & 250 & 1.08 & 1.09 \\
\hline & & 50 & 469 & 555 & 220 & 245 & 250 & 1.11 & 1.14 \\
\hline & & 75 & 469 & 535 & 205 & 242 & 250 & 1.18 & 1.22 \\
\hline \multirow[t]{4}{*}{$\mathrm{X} 4$} & 18.1 & 0 & 513 & 995 & 319 & 297 & 297 & 0.93 & 0.93 \\
\hline & & 25 & 513 & 974 & 310 & 296 & 297 & 0.96 & 0.96 \\
\hline & & 50 & 513 & 953 & 298 & 296 & 297 & 0.99 & 1.00 \\
\hline & & 75 & 513 & 932 & 278 & 295 & 297 & 1.06 & 1.07 \\
\hline \multirow[t]{4}{*}{ X5 } & 12.9 & 0 & 654 & 2465 & 520 & 395 & 395 & 0.76 & 0.76 \\
\hline & & 25 & 654 & 2438 & 505 & 395 & 395 & 0.78 & 0.78 \\
\hline & & 50 & 654 & 2411 & 485 & 395 & 395 & 0.81 & 0.82 \\
\hline & & 75 & 654 & 2384 & 452 & 395 & 395 & 0.87 & 0.87 \\
\hline \multirow[t]{4}{*}{ X6 } & 50.0 & 0 & 834 & 243 & 75 & 144 & 144 & 1.93 & 1.93 \\
\hline & & 25 & 834 & 183 & 73 & 110 & 144 & 1.50 & 1.98 \\
\hline & & 50 & - & - & - & - & - & - & - \\
\hline & & 75 & - & - & - & - & - & - & - \\
\hline \multirow[t]{4}{*}{$\mathrm{X} 7$} & 25.6 & 0 & 953 & 652 & 285 & 358 & 358 & 1.26 & 1.26 \\
\hline & & 25 & 953 & 613 & 277 & 340 & 358 & 1.23 & 1.29 \\
\hline & & 50 & 953 & 572 & 266 & 321 & 358 & 1.21 & 1.35 \\
\hline & & 75 & 953 & 530 & 248 & 300 & 358 & 1.21 & 1.44 \\
\hline \multirow{4}{*}{$\mathrm{X} 8$} & 35.3 & 0 & 2778 & 1364 & 482 & 784 & 784 & 1.63 & 1.63 \\
\hline & & 25 & 2778 & 1199 & 468 & 696 & 784 & 1.49 & 1.67 \\
\hline & & 50 & 2778 & 1024 & 450 & 601 & 784 & 1.34 & 1.74 \\
\hline & & 75 & - & - & - & - & - & - & - \\
\hline \multirow[t]{7}{*}{$\mathrm{X} 9$} & 50.5 & 0 & 2745 & 604 & 227 & 362 & 362 & 1.60 & 1.60 \\
\hline & & 25 & 2745 & 445 & 221 & 268 & 362 & 1.22 & 1.64 \\
\hline & & 50 & - & - & - & - & - & - & - \\
\hline & & 75 & - & - & - & - & - & - & - \\
\hline & & & & & & & Avg. & 1.17 & 1.26 \\
\hline & & & & & & & St. dev. & 0.25 & 0.32 \\
\hline & & & & & & & $\mathrm{COV}$ & 0.22 & 0.25 \\
\hline
\end{tabular}

$$
R_{d}=\phi R_{n}=1.2 G_{n}+1.6 Q_{n}
$$

where $\phi$ is the resistance factor, which is to be determined. By rearranging Eqs. (52)-(55), the reliability index can be evaluated as:

$$
\beta=\frac{\ln \left[\frac{M_{m} P_{m} F_{m}}{1.05+\kappa} \cdot \frac{1.2+1.6 \kappa}{\phi}\right]}{\sqrt{\left(V_{P}\right)^{2}+\left(V_{M}\right)^{2}+\left(V_{F}\right)^{2}+\frac{\left(1.05 V_{G}\right)^{2}+\left(V_{Q} \kappa\right)^{2}}{(1.05+\kappa)^{2}}}}
$$

and consequently:

$$
\phi=\frac{M_{m} P_{m} F_{m} \frac{1.2+1.6 \kappa}{1.05+\kappa}}{\exp \left\{\beta \sqrt{\left(V_{P}\right)^{2}+\left(V_{M}\right)^{2}+\left(V_{F}\right)^{2}+\frac{\left(1.05 V_{G}\right)^{2}+\left(V_{Q} \kappa\right)^{2}}{(1.05+\kappa)^{2}}}\right\}}
$$

Fig. 16 plots the resistance factors calculated using Eq. (57) as a function of the load ratio $\kappa$. A target reliability index of 3.5 was used, which is the recommended value for connections in the North American Standard [20]. Considering that the practical range of load ratios

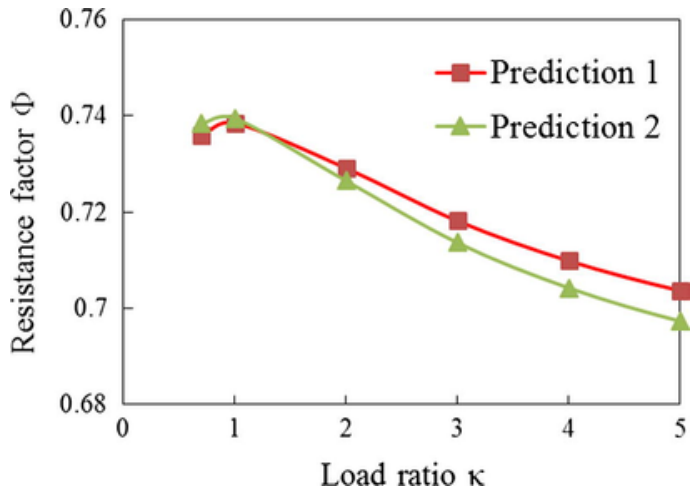

Fig. 16. Resistance factors calculated using AISC approach.

reaches up to 5 for steel structures, the minimum resistance factor over this range is 0.7 for both models. The design equation proposed within the framework of AISC specifications thus becomes:

$$
P_{b, d}=0.7 \chi P_{y}
$$

Additional Monte-Carlo simulations were run to more accurately assess the reliability level of the two design models. The failure fre- 
quency was again evaluated using a limit state function:

Table 7

Statistical distributions used in North American Standard.

\begin{tabular}{llllll}
\hline Name & Distribution & Nominal & Mean & COV & Reference \\
\hline G & Normal & $G_{n}$ & $1.05 G_{n}$ & 0.1 & {$[24]$} \\
$\mathrm{Q}$ & Gumbel & $Q_{n}$ & $Q_{n}$ & 0.25 & {$[24]$} \\
$\mathrm{M}$ & Lognormal & - & 1.1 & 0.1 & {$[26]$} \\
P-prediction 1 & Lognormal & - & 1.24 & 0.18 & Fitted by authors \\
P-prediction 2 & Lognormal & - & 1.16 & 0.15 & Fitted by authors \\
F & Lognormal & - & 1.0 & 0.1 & {$[26]$} \\
\hline
\end{tabular}

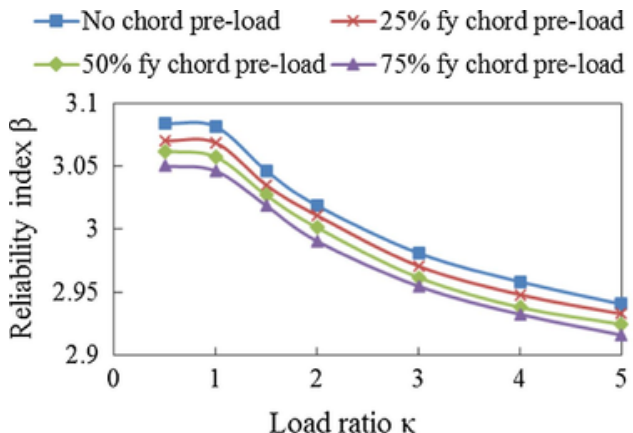

(a) Prediction 1

$$
P_{f}=P_{f}(P \cdot R-E<0)
$$

where $P$ is the ratio of the actual resistance to the design model prediction, $R$ is the resistance predicted by the design model, and $E=G+Q$ is the load effect. The distributions of the variables $h_{0}, h_{1}, t, E, f_{y}, P$, $G$ and $Q$ were adopted from Tables 5 and 7. Fig. 17 shows the reliability index obtained from Monte-Carlo simulations for specimen $\mathrm{X} 1$ at various levels of chord pre-load, using a resistance factor of $\phi=0.7$. Given the simplified assumptions underlying Eq. (57) it is not entirely surprising that the initially proposed resistance factor of 0.7 does not achieve the target reliability level. By trial and error a re-
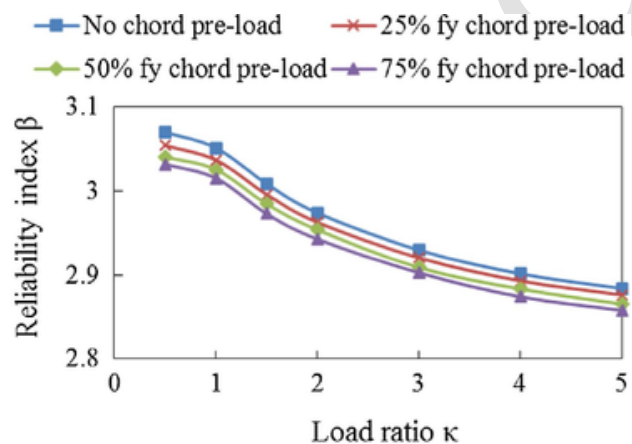

(b) Prediction 2

Fig. 17. Reliability levels of specimen X1 using $\phi=0.7$.

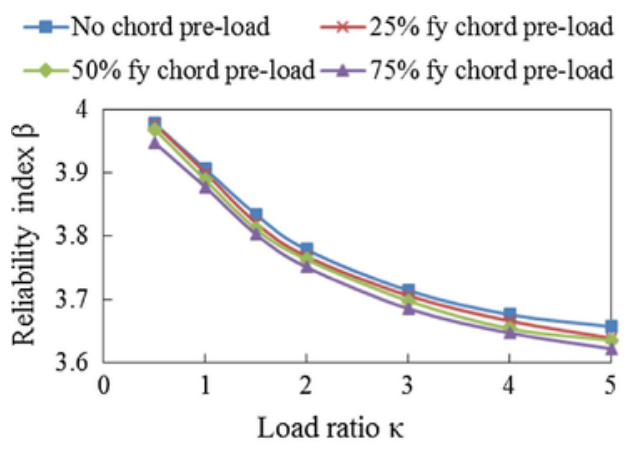

(a) Prediction 1

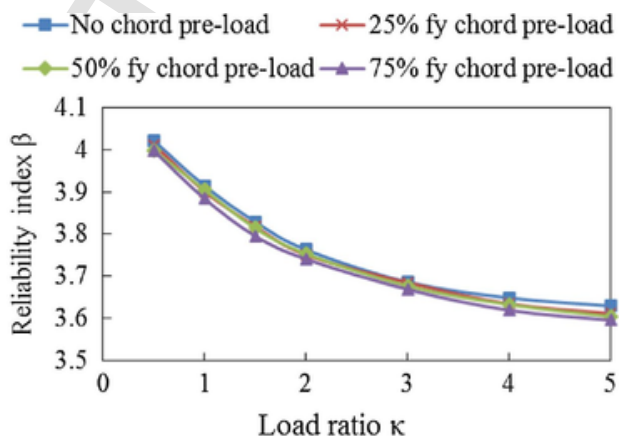

(b) Prediction 2

Fig. 18. Reliability levels of specimen X1 using $\phi=0.55$.

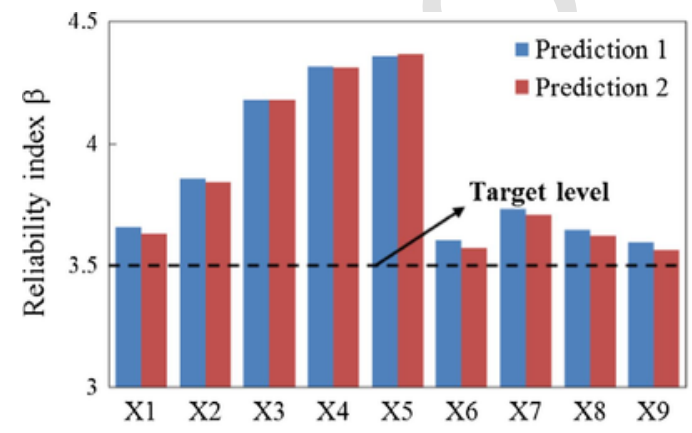

(a) No chord pre-load

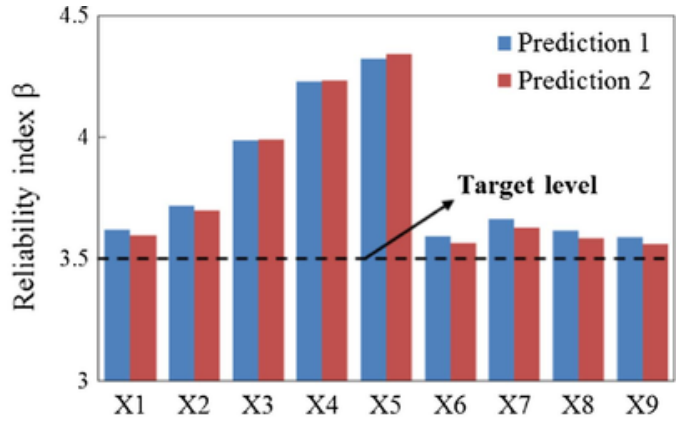

(b) $75 \%$ chord pre-load

Fig. 19. Reliability levels of all $X$-joints for a resistance factor $\phi=0.55$ anda load ratio $\kappa=5$. 
sistance factor of 0.55 was found to be satisfactory, as shown in Figs. 18 and 19.

\section{Conclusions}

This paper presents a new method for the design of equal-width RHS X-joints, for which side wall failure is the critical failure mode. The method accounts for the possible presence of a compressive chord pre-load. The approach employs a slenderness parameter which is based on a rational analysis of an infinitely long plate subject to a combination of a localized distributed load and longitudinal compression. A Rayleigh-Ritz approximation was thereby used to obtain the critical elastic buckling stress.

A detailed FE model was developed which includes material and geometric non-linearity and accounts for imperfect geometry. The model was first verified against experimental data including RHS $\mathrm{X}$-joints of widely varying sizes, wall slenderness values and material properties and was found to yield highly accurate results. In a next stage, parametric studies were conducted in which various levels of compressive pre-load were applied to the chord members. It was found that, generally, the chord pre-load does not have a major effect on the side wall buckling load, although a more substantial reduction of the buckling load was observed for the specimens with the most slender chord walls.

A new design equation was proposed which strongly outperforms the current CIDECT design rule for side wall failure. Reliability analyses were conducted within the frameworks of both the Eurocode and the AISC specifications. A partial safety factor of $\gamma_{M}=1.6$ was recommended for use within the Eurocode and a resistance factor $\phi=0.55$ was proposed for design according to the AISC specifications.

\section{References}

[1] J. Wardenier, J.A. Packer, X.L. Zhao, G.J.v.d. Vegte, Hollow sections in structural applications, 2010

[2] J.A. Packer, J. Wardenier, X.L. Zhao, G.J. van Der Vegte, Y. Kurobane, Design guide for rectangular hollow section (RHS) joints under predominantly loading, 2009.

[3] J.A. Packer, Web crippling of rectangular hollow sections, J Struct Eng 110 (1984) 2357-2373.
[4] L.H. Lu, G.D. de Winkel, Y. Yu, J. Wardenier, Deformation limit for the ultimate strength of hollow section joints, Tubular Structures VI, Balkema, Rotterdam, The Netherlands, 1994.

[5] J. Becque, S. Cheng, Side-wall buckling of equal-width RHS truss X-joints (under review), J Struct Eng (2016). [in preparation].

[6] J. Becque, T. Wilkinson, A new design equation for side wall buckling of RHS truss X-joints, CRC Press, 2015.

[7] W.S. Hemp, The theory of flat panels buckled in compression, Aeronautical Research Council, 1945.

[8] J. Becque, T. Wilkinson, Experimental investigation of the static capacity of grade C450 RHS T and X truss joints, CRC Press, 2011.

[9] G. Davies, J. Packer, Analysis of web crippling in a rectangular hollow section, Proc Inst Civ Eng 83 (1987) 785-798.

[10] J. Wardenier, The static strength of welded lattice girder joints in structural hollow sections, Delft University of Technology, 1980. BI-78-20-0063.4.3470.

[11] J. Wardenier, Hollow section joints, Delft University Press, Netherlands, 1982.

[12] Y. Yu, The static strength of uniplanar and multiplanar connections in rectangular hollow sections, Delft University of Technology, 1997.

[13] S.P. Timoshenko, J.M. Gere, Theory of elastic stability, 2nd ed., McGraw-Hill, New York, 1961.

[14] ABAQUS. ABAQUS analysis users' manual - version 6.14-1. USA: ABAQUS INC.; 2014.

[15] J. Becque, T. Wilkinson, A. Syam, Experimental investigation of X and T truss connections in C450 cold-formed rectangular hollow sections, The University of Sydney, Sydney, 2011.

[16] S. Guo, Side wall buckling of RHS truss joints, MSc University of Sheffield, 2014.

[17] J.C. Platt, Side-wall behaviour in full-width rectangular hollow section joints, PhD University of Nottingham, 1984.

[18] ECCS. EN1993-1-1: design of steel structures. Brussels: BSI; 2005.

[19] ECCS. EN1990: basis of structural design. BSI; 2002.

[20] AISC, Specification for structural steel buildings, 2010. Chicago.

[21] R.V. Coile, Reliability-based decision making for concrete elements exposed to fire, $\mathrm{PhD}$ thesis University of Gent, 2015.

[22] M. Holicky, M. Sykora, Stochastic models in analysis of structural reliability, In: Proceedings of the international symposium on stochastic models in reliability engineering, life sciences and operation management, Beer Sheva, Israel, 2010

[23] JCSS. JCSS probabilistic model code. Zurich: Joint committee on structural safety; 2001.

[24] B. Ellingwood, Development of a probability based load criteria for American National Standard, 1980

[25] The MathWorks Inc., Matlab user guide. Natick, MA; 2015.

[26] L.E. Hsiao, W.W. Yu, T.V. Galambos, AISI LRFD method for cold-formed steel structural members, In: 9th International specialty conference on cold-formed steel structures, 1988. 